\title{
Post-fire behaviour of eccentrically loaded reinforced concrete columns confined by circular steel tubes
}

\author{
Faqi Liu ${ }^{\text {a,b }}$, Hua Yang a,b Leroy Gardner ${ }^{\mathrm{c}}$
}

${ }^{a}$ Key Lab of Structures Dynamic Behavior and Control (Harbin Institute of Technology), Ministry of Education, Heilongjiang, Harbin, 150090, China

${ }^{\mathrm{b}}$ School of Civil Engineering, Harbin Institute of Technology, Heilongjiang, Harbin, 150090, China

${ }^{c}$ Department of Civil and Environmental Engineering, South Kensington Campus, Imperial College London, SW7 2AZ, UK

\begin{abstract}
:
The post-fire behaviour of eccentrically loaded reinforced concrete columns confined by circular steel tubes, also known as circular steel tube confined reinforced concrete (STCRC) columns, is investigated in this paper. A total of 12 experiments were conducted on eccentrically loaded circular STCRC stub columns after exposure to the ISO 834 standard fire, including both the heating and cooling phases. The temperatures across the tested sections, the axial load versus lateral displacement responses and the strains in the steel tubes were all measured and discussed. A finite element (FE) model was developed using the program ABAQUS, and validated against the test results from the present study, as well as related studies. Parametric studies were then performed to identify the influences of key parameters on the residual capacity of the eccentrically loaded STCRC columns, including eccentricity ratio, heating time, cross-sectional diameter, slenderness ratio, material strengths, steel tube to concrete area ratio and reinforcement ratio. Finally, a simplified method was proposed for predicting the residual load-bearing capacity of the eccentrically loaded STCRC columns after fire exposure.
\end{abstract}

Key words: Circular steel tube confined reinforced concrete; eccentrically loaded; experiments; finite element modelling; post-fire; residual capacity; testing 


\begin{tabular}{|c|c|}
\hline \multicolumn{2}{|c|}{ Nomenclature } \\
\hline$A \mathrm{~b}$ & cross-sectional area of reinforcing bars \\
\hline$A_{\mathrm{c}}$ & cross-sectional area of concrete core \\
\hline$A_{\mathrm{s}}$ & cross-sectional area of steel tube \\
\hline$A$ & cross-sectional area of composite section, $A=A_{\mathrm{s}}+A_{\mathrm{c}}+A_{\mathrm{b}}$ \\
\hline$D$ & outer diameter of cross-section \\
\hline$e$ & load eccentricity \\
\hline$E \mathrm{~b}$ & Young's modulus of reinforcement at ambient temperature \\
\hline$E_{\mathrm{bT}}$ & Young's modulus of reinforcement after fire exposure \\
\hline$E_{\mathrm{c}}$ & Young's modulus of concrete at ambient temperature \\
\hline$E_{\mathrm{cT}}$ & Young's modulus of concrete after fire exposure \\
\hline$E_{\mathrm{S}}$ & Young's modulus of steel at ambient temperature \\
\hline$E_{\mathrm{ST}}$ & Young's modulus of steel after fire exposure \\
\hline$f_{\mathrm{b}}$ & yield strength of reinforcement at ambient temperature \\
\hline$f_{\mathrm{bT}}$ & yield strength of reinforcement after fire exposure \\
\hline$f_{\mathrm{c}}^{\prime}$ & concrete cylinder strength \\
\hline$f_{\mathrm{cT}} \mathrm{T}^{\prime}$ & concrete cylinder strength after fire exposure \\
\hline$f_{\mathrm{y}}$ & yield strength of steel \\
\hline$f_{\mathrm{yT}}$ & yield strength of steel after fire exposure \\
\hline$k$ & factor accounting for delay of temperature rise of concrete \\
\hline$L$ & length of column \\
\hline$N_{\text {ecc, } \mathrm{T}}$ & load-bearing capacity of eccentrically loaded column after fire exposure \\
\hline$N_{\text {axi,T }}$ & load-bearing capacity of axially loaded column after fire exposure \\
\hline$N_{\mathrm{u}}$ & cross-sectional capacity of composite column \\
\hline$r$ & radius of steel tube, $r=D / 2$ \\
\hline$t_{\mathrm{h}}$ & heating time to the maximum fire temperature \\
\hline$t_{\mathrm{s}}$ & wall thickness of the steel tube \\
\hline$T$ & temperature \\
\hline
\end{tabular}




\begin{tabular}{|ll|}
\hline$T_{\max }$ & maximum temperature achieved during the heating and cooling phases \\
$\alpha_{\mathrm{b}}$ & ratio of reinforcement, $\alpha_{\mathrm{b}}=A_{\mathrm{b}} /\left(A_{\mathrm{c}}+A_{\mathrm{b}}\right)$ \\
$\alpha_{\mathrm{s}}$ & steel tube to concrete area ratio, $\alpha_{\mathrm{s}}=A_{\mathrm{s}} / A_{\mathrm{c}}$ \\
$\varepsilon$ & strain \\
$\lambda$ & slenderness ratio, $\lambda=L / i$, where $i$ is the radius of gyration \\
$\chi_{\mathrm{e}}$ & buckling reduction factor \\
$\chi_{\mathrm{T}}$ &
\end{tabular}




\section{Introduction}

Reinforced concrete columns confined by steel tubes, also referred as steel tube confined reinforced concrete (STCRC) columns, are composite members with outer steel tubes terminated at the beam-to-column connections. The steel tube in STCRC columns acts principally as hoop reinforcement, maximising its confinement to the concrete and reducing the possibility of local buckling, compared with concrete-filled steel tubular (CFST) columns. The confinement effect greatly enhances the strength and ductility of the in-filled concrete. Therefore STCRC columns possess high load-bearing capacity and excellent seismic performance. The desired break in continuity of the steel tube enables the reinforced concrete beam to STCRC column connections to be designed and constructed following the same approach as for conventional reinforced concrete structures, which avoids the complexities associated with reinforced concrete beam to CFST column connections $[1,2]$.

Previous studies, conducted by Tommi et al. [3-5], Sun et al. [6], Aboutaha et al. [7,8], Han et al. [9,10], Liu et al. [11-13] and Yu et al. [14], have all focused on the compression behaviour or seismic performance of steel tube confined reinforced (or plain) concrete columns at ambient temperature. Following on from recent research by the authors on the post-fire behaviour of axially loaded STCRC stub columns [1] and STCRC slender columns[2], the post-fire behaviour of eccentrically loaded STCRC columns is investigated herein.

A total of 12 specimens were firstly exposed to the ISO 834 standard fire conditions [15] and were then loaded eccentrically, to investigate the residual behaviour of these STCRC columns and provide benchmark data for the verification of the finite element (FE) model. The temperatures of the steel tube, reinforcing bars and concrete, as well as the load versus lateral displacement curves, strains in the outer steel tube and failure modes were all measured and analysed. A FE model was developed in the program ABAQUS, using a sequentially coupled thermal-stress analysis, by first performing a pure heat transfer analysis and then a stress analysis. Parametric studies were conducted to investigate the influences of key parameters on the residual capacity of the eccentrically loaded STCRC columns after fire exposure. Finally, a simplified method was proposed for predicting the load-bearing capacity of eccentrically loaded STCRC columns after fire exposure. 


\section{Experimental investigation}

\subsection{Test specimens}

A total of 12 circular STCRC stub columns were tested after fire exposure. The key test parameters were concrete compressive strength (C30, C50) and load eccentricity e $(25 \mathrm{~mm}, 50 \mathrm{~mm})$, which were also used to label the specimens. The specimen labelling system can be explained by the means of an example - consider specimen $\mathrm{C} 30-\mathrm{e} 25-\mathrm{a}$; $\mathrm{C} 30$ is the concrete grade, $e$ denotes that the load was applied eccentrically, 25 is the load eccentricity in $\mathrm{mm}$, and the final letter identifies different specimens in a specimen group with the same parameters. Details of the parameters of the specimens, including the cross-section diameter $D$, the thickness of steel tube $t_{\mathrm{s}}$, the length of specimens $L$, the load eccentricity $e$, the steel tube to concrete area ratio $\alpha_{\mathrm{s}}\left(\alpha_{\mathrm{s}}=A_{\mathrm{s}} / A_{\mathrm{c}}\right)$, the reinforcement ratio $\alpha_{\mathrm{b}}$ $\left(\alpha_{\mathrm{b}}=A_{\mathrm{b}} /\left(A_{\mathrm{c}}+A_{\mathrm{b}}\right)\right)$ and the heating time $t_{\mathrm{h}}$ (the time corresponding to the maximum furnace temperature), are presented in Table 1.

The steel tubes in the circular STCRC columns were cold-formed from steel sheets and seam welded. Two $300 \mathrm{~mm} \times 300 \mathrm{~mm} \times 20 \mathrm{~mm}$ steel plates were welded to the top and bottom ends of the columns. Two gaps, with a width of $10 \mathrm{~mm}$, were introduced into the steel tube, $50 \mathrm{~mm}$ away from each end plate, in order to prevent the load being applied to the steel tube directly. Six longitudinal reinforcing bars with a diameter of $20 \mathrm{~mm}$ were tied at $200 \mathrm{~mm}$ intervals with $8 \mathrm{~mm}$ stirrups. The longitudinal reinforcing bars were welded and anchored to the end plates, to prevent the possibility of bond failure due to insufficient anchorage. The concrete cover from the outer perimeter of the reinforcing bars to the concrete edge was $20 \mathrm{~mm}$. Details of the test specimens are shown in Fig.1.

An additional stub column, with a length of $500 \mathrm{~mm}$ (Fig.2) and the same constituent components (steel tube, reinforcing bars and concrete) as the other test specimens, was specially fabricated to measure temperatures in the specimens during the heating and cooling phases. The gaps introduced in the steel tube could act as vent holes for moisture produced during the test, as shown in Fig.2. Type $\mathrm{K}$ thermocouples, with a diameter of $1.0 \mathrm{~mm}$, were employed to measure the temperatures of the steel tube, reinforcing bars and concrete in several locations at two cross-sections, which were $150 \mathrm{~mm}$ away from each end plate. The uniformity of temperature along the longitudinal direction could then be verified by comparing the corresponding temperatures at the two different heights. The 
layouts of the thermocouples are shown in Fig.2.

The steel tube, reinforcing bars and concrete used for the test specimens examined herein came from the same batch of materials as used in previous tests by the authors on circular STCRC stub columns [1] and slender columns [2]. The properties of the steel tube and reinforcing bars were tested by performing tensile coupon tests and were presented in [1,2]. Herein, their properties are briefly described. The yield strength of the steel tube was $318.9 \mathrm{~N} / \mathrm{mm}^{2}$ and $295.2 \mathrm{~N} / \mathrm{mm}^{2}$, respectively, before fire exposure and after 30 minutes' heating. The yield strength of the longitudinal reinforcement and stirrups were $357.4 \mathrm{~N} / \mathrm{mm}^{2}$ and $435.4 \mathrm{~N} / \mathrm{mm}^{2}$, respectively, before fire exposure. The concrete cube strengths were tested at 28 days and the test day of the specimens $[1,2]$. For the grade C30 and C50 concrete, the cube strength reached $53.8 \mathrm{~N} / \mathrm{mm}^{2}$ and $76.3 \mathrm{~N} / \mathrm{mm}^{2}$, respectively, at the test days of the specimens.

\subsection{Test setup and procedure}

Regarding the residual strength of the concrete after fire exposure, studies on concrete material [16-18] and concrete members [19,20] have confirmed that the determination of properties in the unstressed condition during the heating and cooling phases is more conservative than in the stressed condition. Hence, the STCRC columns were heated in an unstressed condition within a specially built furnace for testing structural members. Details of the furnace may be found in [1].

Fires in an enclosure usually undergo three stages: i) fire growth, ii) steady burning and iii) decay. Since it is not straightforward to obtain accurate fire temperature versus time relationships for real fires due to the inherent complexities and uncertainty of their nature, for the purposes of fire safety design, some approximate fire temperature versus time relationships have been developed. The ISO 834-1975 Standard [15] provides a standard fire curve, including heating and cooling phases. EN 1991-1-2 [21] specifies a parametric fire model, in which the decay rate is also based on the ISO 834-1975 Standard. When the parameter $\Gamma=1$, the parametric fire curve in EN 1991-1-2 almost coincides with the ISO 834 standard fire curve. In the tests performed in the present study, the furnace temperature was increased following the ISO 834 standard fire curve, including both the heating and cooling phases. The heating time was taken as $30 \mathrm{~min}$, and the corresponding cooling time (down to $200{ }^{\circ} \mathrm{C}$ ) was about $60 \mathrm{~min}$. Therefore the total exposure time was about $90 \mathrm{~min}$. This 
corresponds to short duration fires, after which retrofitting of the structural members may be possible. Longer heating times were not possible in the experiments due to limitations in the gas supply capacity, but longer heating times (up to 3 hours) were considered in the FE analysis, see Section 4. The ambient temperature was $23{ }^{\circ} \mathrm{C}$ before the heating test. Both of the end plates were fully protected with ceramic fibre blankets for all specimens, to prevent heat being conducted into specimens via the end plates. The temperatures of the furnace, steel tube, reinforcing bars and concrete were monitored and recorded during the heating and cooling phases.

After cooling to ambient temperature, the specimens were loaded eccentrically using a $5000 \mathrm{kN}$ hydraulic actuator. Knife-edges were used to allow rotation about the axis of load eccentricity. Therefore pinned-pinned end conditions were achieved. The effective length of all specimens was $900 \mathrm{~mm}$, which included the specimen length of $750 \mathrm{~mm}$, plus the height of the knife-edges and the thickness of the end plates. Linear variable displacement transducers were placed horizontally to measure lateral displacements. Longitudinal and transverse strains in the steel tube were measured using strain gauges.

\subsection{Test results and discussions}

All tested STCRC columns failed by local buckling of the steel tube on the compression side along with concrete crushing. Horizontal cracks in the concrete were also observed on the tension side at the mid-height. Crushing of the concrete on the compression side and cracking of the concrete on the tension side appeared to intensify with the increasing of load eccentricity, as shown in Fig.3. Despite the crushing and cracking, the concrete remained essentially intact, owing to the confinement effect of the outer steel tube.

The test specimens in this study were heated simultaneously with the axially loaded stub columns reported previously [1]. The measured furnace temperatures, together with those for the axially loaded slender columns [2], are shown in Fig.4. It can be seen that the measured furnace temperatures closely follow the ISO 834 standard fire curve. Furthermore, the variation of the measured furnace temperatures between the stub column and slender column tests is small, confirming the reproducibility and robustness of the furnace. According to the ISO 834-1975 Standard, following the attainment of the desired heating time (30 minutes in the present study), the 
furnace temperature should be controlled to decrease linearly at a rate of $10.417{ }^{\circ} \mathrm{C} / \mathrm{min}$ down to 200 ${ }^{\circ} \mathrm{C}$, after which, no cooling rate is specified. In the test, despite all gas burners being turned off upon reaching $200{ }^{\circ} \mathrm{C}$, it took some time to cool the furnace temperature to ambient temperature, as shown in Fig.4. This may be attributed to the heat emitted from the furnace insulation materials and test specimens.

The deviation of the measured furnace temperatures from the ISO 834-1975 standard fire curve during the heating and cooling phases is presented in Fig.5. The deviation exceeds the tolerance specified in ISO 834-1975 for the first 3 min, which may be associated with the rapid increase of the ISO 834 standard fire temperature during the first few minutes. After the first 3 minutes of the test, the deviation is within the specified tolerance. Overall, the furnace temperature may be observed to follow the standard fire curve accurately during both the heating and cooling phases. The measured temperatures of the steel tube, reinforcing bars and concrete are shown in Fig.6, which were also presented in [1]. The achieved maximum temperatures decrease from the outer steel tube to the concrete centre, and the corresponding time increases significantly. This delay of temperature rise in the concrete was also observed in [2], and can be attributed to the high thermal capacity of concrete and the protection provided by surrounding materials. The uniformity of temperature along the longitudinal direction also can be confirmed by comparing the corresponding temperatures at different heights.

The load versus lateral displacement curves of the specimens are presented in Fig.7. The load-bearing capacity of specimen C50-e25-b is comparatively low (Fig.7(c)), due to a concrete consolidation problem. This specimen was excluded from later analyses. All specimens exhibited a gradual unloading response with increasing deformation, confirming the ductile behaviour of STCRC columns after fire exposure. The influences of load eccentricity on the load-bearing capacity are illustrated in Fig.8, by comparing the peak loads of the eccentrically loaded columns with those of the axially loaded columns [1]. The presence of the load eccentricity significantly decreases the load-bearing capacity of STCRC columns after fire exposure. Take the specimens in group C30 for example, the load bearing capacity decreases by around $33 \%$ and $50 \%$ for specimens with eccentricity of $25 \mathrm{~mm}$ and $50 \mathrm{~mm}$ respectively relative to the axially loaded specimens. The 
reduction in axial capacity arises primarily due to the presence of the co-existant bending moment, but also reflects that higher confined concrete strengths can be achieved for specimens loaded predominantly in compression than those mainly subjected to bending.

Typical vertical and horizontal strains in the steel tube are depicted in Fig.9. The vertical strains adjacent to the gap are approximately zero, and no failure was observed at the gap, confirming the feasibility of the solution to prevent the steel tube from being loaded directly. The horizontal strains in the steel tube at the mid-height are close to the vertical strains, which may be attributed to the bond stress and friction force between the steel tube and the concrete. The horizontal strains at the extreme compressive fibre (point B) are larger than at the extreme tensile fibre (point A), which may be caused by the expansion of the concrete in the compression zone.

\section{Numerical modelling}

Following the experiments, a 3D finite element (FE) model was developed using the program ABAQUS, to investigate the behaviour and residual load-carrying capacity of eccentrically loaded STCRC columns after fire exposure. A key feature of the FE model is that the confinement effect can be modelled explicitly by defining the interaction behaviour between the steel tube and the concrete. Global buckling and local buckling of the steel tube can also be captured. A pure heat transfer analysis was firstly conducted to identify the thermal distributions. Following that, the thermal analysis results were imported into a subsequent mechanical analysis to study the performance of the STCRC columns under load.

\subsection{Thermal analysis}

A transient heat transfer analysis was performed to simulate the process of heat transmission from the fire to the outer steel tube via convection and radiation, and then into the columns by conduction. The convective heat transfer coefficient, resultant emissivity and thermal resistance at the steel tube and concrete interface were set to $25 \mathrm{~W} /\left(\mathrm{m}^{2} \mathrm{~K}\right), 0.5$ and $0.01\left(\mathrm{~m}^{2} \mathrm{~K}\right) / \mathrm{W}$, respectively, which were found to generate accurate temperature predictions [1,2]. The ambient temperature was set to $20{ }^{\circ} \mathrm{C}$, and the ISO 834 standard fire condition [15], including both the heating and cooling phases, was applied as the thermal load.

The temperature-dependent conductivity and specific heat of the materials were defined according to 
the models proposed by Lie [22]. The influence of water evaporation on the thermal distribution was considered and the moisture content was assumed to be 5\% by weight [23]. The densities of the materials were considered to be independent of temperature, and taken as $7850 \mathrm{~kg} / \mathrm{m}^{3}$ and 2350 $\mathrm{kg} / \mathrm{m}^{3}$ for the steel and concrete, respectively.

The steel tube, concrete and reinforcement were modelled with the 4-node quadrilateral shell element (DS4), 8-node linear solid element (DC3D8) and 2-node truss element (DC1D2), respectively, in the thermal analysis model.

\subsection{Mechanical analysis}

For the steel tube and reinforcement, an elastic-perfectly plastic stress-strain model was adopted in accordance with previous studies on the post-fire behaviour of axially loaded STCRC stub columns [1] and STCRC slender columns [2]. The yield strength and elastic modulus of the structural steel and reinforcement after fire exposure were determined from the models proposed by Tao et al. [24], given as follows:

For structural steel:

$$
f_{\mathrm{yT}}= \begin{cases}f_{\mathrm{y}} & T_{\max } \leq 500^{\circ} \mathrm{C} \\ {\left[1-2.33 \times 10^{-4}\left(T_{\text {max }}-500\right)-3.88 \times 10^{-7}\left(T_{\text {max }}-500\right)^{2}\right] f_{\mathrm{y}}} & T_{\text {max }}>500^{\circ} \mathrm{C}\end{cases}
$$

For reinforcement:

$$
f_{\mathrm{bT}}= \begin{cases}f_{\mathrm{b}} & T_{\max } \leq 500^{\circ} \mathrm{C} \\ {\left[1-5.82 \times 10^{-4}\left(T_{\max }-500\right)\right] f_{\mathrm{b}}} & T_{\max }>500^{\circ} \mathrm{C}\end{cases}
$$

For both structural steel and reinforcement:

$$
E_{\mathrm{sT}}= \begin{cases}E_{\mathrm{s}} & T_{\max } \leq 500^{\circ} \mathrm{C} \\ {\left[1-1.30 \times 10^{-4}\left(T_{\max }-500\right)\right] E_{\mathrm{s}}} & T_{\max }>500^{\circ} \mathrm{C}\end{cases}
$$

where $T_{\max }$ is the maximum temperature ever achieved in the relevant material during the heating and cooling phases, $f_{\mathrm{y}}$ and $f_{\mathrm{b}}$ are the yield strengths of the structural steel and reinforcement, respectively, before fire exposure, and $f_{\mathrm{yT}}$ and $f_{\mathrm{bT}}$ are the corresponding residual yield strengths after fire exposure. $E_{\mathrm{s}}$ and $E_{\mathrm{sT}}$ are the elastic moduli of the structural steel before and after fire exposure, respectively. For the reinforcement, $E_{\mathrm{s}}$ and $E_{\mathrm{s} T}$ in Eq.(3) should be replaced by $E_{\mathrm{b}}$ and $E_{\mathrm{b}}$, respectively.

The concrete stress-strain model, proposed by Han et al. [25], which has been successfully used to 
simulate the behaviour of STCRC columns [1,2], steel tube confined plain concrete columns [14] and CFST columns [26], was adopted in this study. The initial elastic modulus $E_{\mathrm{c}}$ was taken as $4700 \sqrt{f_{c}^{\prime}} \mathrm{N} / \mathrm{mm}^{2}$, according to the ACI specification [27]. The concrete compressive strength and corresponding strain, and the elastic modulus after fire exposure can be determined as follows [28]:

$$
\begin{gathered}
f_{\mathrm{cT}}^{\prime}=\frac{f_{\mathrm{c}}^{\prime}}{1+2.4\left(T_{\max }-20\right)^{6} \times 10^{-17}} \\
\varepsilon_{\mathrm{cT}}^{\prime}=\varepsilon_{\mathrm{c}}^{\prime}\left[1+\left(1500 T_{\text {max }}+5 T_{\max }^{2}\right) \times 10^{-6}\right] \\
E_{\mathrm{cT}}=E_{\mathrm{c}} \frac{f_{\mathrm{cT}}^{\prime} / \varepsilon_{\mathrm{cT}}^{\prime}}{f_{\mathrm{c}}^{\prime} / \varepsilon_{\mathrm{c}}^{\prime}}
\end{gathered}
$$

where $f_{\mathrm{c}}^{\prime}, \varepsilon_{\mathrm{c}}^{\prime}$ and $E_{\mathrm{c}}$ are the concrete cylinder strength, the strain corresponding to the compressive strength and the elastic modulus, before fire exposure, and $f_{\mathrm{cT}}{ }^{\prime}, \varepsilon_{\mathrm{cT}}{ }^{\prime}$ and $E_{\mathrm{cT}}$ are the corresponding values after fire exposure. The typical uniaxial stress-strain curves of the structural steel, the reinforcing bars and the concrete after exposure to different temperatures are presented in Fig. 10.

The tensile stress-strain relationship of the concrete was defined to be linear both in the ascending and descending phases, coinciding with previous studies on axially loaded STCRC columns after fire exposure $[1,2]$. The elastic modulus for the concrete in tension was assumed to be equal to that in compression.

The interaction between the steel tube and concrete in STCRC columns can be defined with the contact interaction algorithm in ABAQUS. The outer surface of the concrete and the inner surface of steel tube were defined to be a contact pair, of which the former was assigned as the master surface and the latter as the slave surface. The "hard" contact model was defined for the contact pair in the normal direction, which means unlimited contact pressure can be transmitted when the surfaces are in contact, and separation is allowed if tensile conditions arise. The tangential behaviour was defined with the Coulomb friction model, which allows a friction coefficient and a shear limit stress to be defined. The friction coefficient and bond strength were taken to be 0.3 and $0.4 \mathrm{~N} / \mathrm{mm}^{2}$, respectively $[1,2]$.

The steel tube, concrete and reinforcement were modelled with the 4-node reduced-integration shell element (S4R), 8-node reduced-integration solid element (C3D8R) and 2-node linear displacement 
truss element (T3D2), respectively. The FE mesh of the stress analysis model was the same as that of the heat transfer analysis model, in order to import the thermal results correctly and efficiently. The residual properties of the steel and concrete depend on the maximum temperature ever achieved during the heating and cooling phases. However, the maximum temperatures across the cross-section of the STCRC columns are not achieved simultaneously, due to the high thermal capacity of the concrete. The user subroutine USDFLD was employed to extract maximum temperatures and read them into the stress analysis. An initial global geometric imperfection was introduced in the form of the first buckling mode shape from a prior eigenvalue analysis scaled by an amplification factor of $L / 1000$, where $L$ is the effective length of the column. For the STCRC columns, load was applied only to the concrete core. However, for the CFST columns examined later in this paper for the model validation, load was applied to the whole cross-section.

\subsection{Validation of the FE model}

The heat transfer model has already been validated against the results of tests on STCRC stub columns [1] and STCRC slender columns [2] subjected to the ISO 834 standard fire including the heating and cooling phases, and square and rectangular CFST columns [29,30] subjected to the ISO 834 standard fire. Therefore the aim of this section is to evaluate the ability of the FE model to simulate the structural behaviour of eccentrically loaded STCRC columns. Comparisons of the FE and experimental axial load versus lateral displacement curves for the tested STCRC columns are presented in Fig.11, showing reasonable agreement and demonstrating the ability of the FE models to capture the response of eccentrically loaded STCRC columns after fire exposure.

The FE model was also validated against test results from the eccentrically loaded circular CFST columns [31,32]. Details of the circular CFST stub columns and slender columns are presented in Table 2 and Table 3, respectively, where $L$ is the length of the columns between hinges. An initial imperfection of $L / 600$ was introduced for the simulation of the slender columns, according to the recommendations of Portolés et al. [33]. Fig.12 shows comparisons of the test and FE load versus lateral displacement curves for the CFST columns, revealing generally good agreement, both in the ascending branch and the post-peak branch.

The test and FE load-bearing capacities of the 12 eccentrically loaded STCRC columns after fire 
exposure from the present study, together with the 21 axially loaded STCRC stub columns [1] and the 14 axially loaded STCRC slender columns [2] before and after fire, the 16 eccentrically loaded CFST stub columns [31] and the 8 eccentrically loaded CFST slender columns [32] before fire, are shown in Fig.13. The 3 eccentrically loaded CFST slender columns after fire exposure [34], which were used as part of the FE model validation in [2], are also presented in Fig.13. The mean and standard deviation of the ratio of the FE-to-test load-bearing capacity of the above 77 specimens are 1.011 and 0.077 respectively, confirming the accuracy and robustness of the FE model.

\section{Parametric studies and design method}

After validation of the FE model, parametric studies were conducted to identify the influences of the key parameters on the residual capacities of eccentrically loaded STCRC columns after fire exposure. The considered parameters included eccentricity ratio e/r $(r=D / 2)$, heating time $t_{\mathrm{h}}$, cross-section diameter $D$, slenderness ratio $\lambda(\lambda=L / i$, where $i$ is the radius of gyration), concrete compressive strength $f_{\mathrm{c}}$, yield strength of the steel tube $f_{\mathrm{y}}$, yield strength of the reinforcement $f_{\mathrm{b}}$, steel tube to concrete area ratio $\alpha_{\mathrm{s}}$ and reinforcement ratio $\alpha_{\mathrm{b}}$. The ranges of the studied parameters are as follows: $e / r=0-1.0, t_{\mathrm{h}}=0-180 \mathrm{~min}, D=200-1500 \mathrm{~mm}, \lambda=12-60, f_{\mathrm{c}}^{\prime}=24-50 \mathrm{~N} / \mathrm{mm}^{2}, f_{\mathrm{y}}=235-420 \mathrm{~N} / \mathrm{mm}^{2}$, $f_{\mathrm{b}}=335-500 \mathrm{~N} / \mathrm{mm}^{2}, \alpha_{\mathrm{s}}=2.0 \%-4.0 \%, \alpha_{\mathrm{b}}=2.0 \%-6.0 \%$.

The influences of these parameters on the load-bearing capacity of STCRC columns are depicted in Fig.14. As expected, the load-bearing capacity decreases significantly with increasing load eccentricity, due to the co-existent bending moment and the reduced strength benefit arising from concrete confinement. Similar to previous studies on axially loaded STCRC columns [1,2], the load-bearing capacity of the eccentrically loaded STCRC columns also decreases with the increasing heating time and slenderness ratio, and increases with increasing cross-sectional diameter, material strengths, steel tube to concrete area ratio and reinforcement ratio.

Based on the load-bearing capacity of an axially loaded STCRC column $N_{\text {axi,T, }}$, the load-bearing capacity of the eccentrically loaded column $N_{\text {ecc,T }}$ can be obtained by means of a load eccentricity reduction factor $\chi \mathrm{e}$, as follows:

$$
N_{\text {ecc,T }}=\chi_{\mathrm{e}} N_{\text {axi,T }}
$$

The above load eccentricity reduction factor approach is adopted herein, in favour of an axial 
load-bending moment interaction relationship, to simplify the calculations for designers by avoiding the explicit determination of bending moment capacity; this approach also emphasises that STCRC columns are not suitable for resisting high bending moments, due to the possibility of local failure at the discontinuity (i.e. the gap) in the steel tube at the beam to column connections (for $e / r>1.0$ ). This load-eccentricity reduction factor approach for CFST columns is also employed in the Chinese code GB50936-2014 [35]. Derivation of the method and comparison with the full axial load-bending moment interaction relationship [36] is shown in the appendix.

The influences of the key parameters on the reduction factor $\chi_{\mathrm{e}}$ are presented in Fig.15. It can be seen that the reduction factor $\chi_{\mathrm{e}}$ depends mainly on the eccentricity ratio, whereas the influences of other parameters are comparatively small. Based on the above findings, a simplified equation for the reduction factor $\chi_{\mathrm{e}}$ is therefore proposed:

$$
\chi_{\mathrm{e}}=\frac{1}{1+2.4 e / r} \quad(e / r \leq 1.0)
$$

where $e / r$ is the eccentricity ratio and $r=D / 2$.

The load-bearing capacity of an axially loaded STCRC column can be determined using the method proposed in [2], which has been validated against $572 \mathrm{FE}$ results and 35 test results (including 21 stub columns and 14 slender columns), given as follows:

$$
N_{\mathrm{axi}, \mathrm{T}}=\chi_{\mathrm{T}} N_{\mathrm{u}, \mathrm{T}}
$$

where $\chi_{\mathrm{T}}$ is the buckling reduction factor and $N_{\mathrm{u}, \mathrm{T}}$ is the cross-sectional capacity.

The buckling reduction factor $\chi_{\mathrm{T}}$ can be determined as follows [2]:

$$
\chi_{\mathrm{T}}= \begin{cases}1.0 & \lambda<20 \\ 1.0-0.005\left(\lambda+\frac{2 t_{\mathrm{h}}}{D}\right) & \lambda \geq 20\end{cases}
$$

where $\lambda$ is the slenderness ratio, $t_{\mathrm{h}}$ is the heating time in hours, and $D$ is the cross-sectional diameter in metres.

The cross-sectional capacity of STCRC columns can be calculated as follows [1]:

$$
N_{\mathrm{u}, \mathrm{T}}=\bar{f}_{\mathrm{ccT}} A_{\mathrm{c}}+f_{\mathrm{bT}} A_{\mathrm{b}}
$$

where 


$$
\begin{gathered}
f_{\mathrm{bT}}= \begin{cases}f_{\mathrm{b}} & t_{\mathrm{h}} \leq 1.0 \\
\left(1.075-0.075 t_{\mathrm{h}}\right) f_{\mathrm{b}} & 1.0<t_{\mathrm{h}} \leq 3.0\end{cases} \\
\bar{f}_{\mathrm{ccT}}=\left(-1.254+2.254 \sqrt{\left.1+7.94 \frac{f_{\mathrm{rT}}}{\bar{f}_{\mathrm{cT}}^{\prime}}-2 \frac{f_{\mathrm{rT}}}{\bar{f}_{\mathrm{cT}}^{\prime}}\right) \bar{f}_{\mathrm{cT}}^{\prime}}\right. \\
\bar{f}_{\mathrm{cT}}^{\prime}=k \times\left[1-\left(\frac{0.066}{D}-0.008\right) t_{\mathrm{h}}\right] f_{\mathrm{c}}^{\prime} \\
f_{\mathrm{rT}}=\frac{2 t_{\mathrm{s}} f_{\mathrm{yT}}}{D-2 t_{\mathrm{s}}} \\
f_{\mathrm{yT}}=\left(0.02 t_{\mathrm{h}}^{2}-0.15 t_{\mathrm{h}}+1.0\right) f_{y}
\end{gathered}
$$

where $t_{\mathrm{h}}$ is the heating time to the maximum temperature of the fire in hours, $D$ is the cross-sectional diameter in metres, $t_{\mathrm{s}}$ is the wall thickness of the steel tube in metres and $k$ is a parameter accounting for the effect of the delay in temperature rise of the concrete, which is 0.98 and 1.0 for exposed and unexposed columns, respectively.

The predicted reduction factor $\chi_{\mathrm{e}}$ using Eq.(8) is compared with FE results in Fig.16, confirming the accuracy of the Eq.(8). The predicted load-bearing capacities from the design method are compared with FE results and experimental results in Fig.17. The mean and standard deviation of the ratio of design method to FE results are 0.989 and 0.120, respectively, whereas the mean and standard deviation of the ratio of design method to experimental results are 1.017 and 0.069 , respectively.

The limits of the applicability of the design method are as follows: $D=0.2-1.5 \mathrm{~m}, t_{\mathrm{h}}=0-3 \mathrm{~h}, \lambda \leq 60$, $e / r=0-1.0, f_{\mathrm{c}}^{\prime}=20 \mathrm{~N} / \mathrm{mm}^{2}-50 \mathrm{~N} / \mathrm{mm}^{2}, f_{\mathrm{y}}=235 \mathrm{~N} / \mathrm{mm}^{2}-420 \mathrm{~N} / \mathrm{mm}^{2}, f_{\mathrm{b}}=335 \mathrm{~N} / \mathrm{mm}^{2}-500 \mathrm{~N} / \mathrm{mm}^{2}$, $\alpha_{s}=2 \%-4 \%$, and $\alpha_{b}=2 \%-6 \%$.

\section{Conclusions}

The post-fire behaviour of the eccentrically loaded STCRC column has been investigated experimentally and numerically. Twelve specimens were loaded eccentrically after exposed to the ISO 834 standard fire condition, including both the heating and cooling phases. A sequentially coupled thermal-stress analysis model was developed to study the influences of key parameters on the load-bearing capacity of eccentrically loaded STCRC columns. Based on the experimental and numerical results, a simplified design method was proposed for predicting the bearing capacity of 
eccentrically loaded STCRC columns. From this study, following conclusions can be drawn:

(1) The tested eccentrically loaded STCRC stub columns failed by local buckling of the steel tube in the compression zone along with concrete crushing, but, all specimens exhibited fairly ductile behaviour. The inner concrete core remained essentially intact, despite some crushing in the concrete, due to the confinement of the outer steel tube.

(2) The load-bearing capacity of the STCRC column after fire exposure decreases markedly with the increasing of load eccentricity. Load-bearing capacity was found to vary almost linearly with heating time, slenderness ratio, material strengths, steel tube to concrete area ratio and reinforcement ratio.

(3) The reduction factor for load eccentricity depends predominantly on the load eccentricity ratio, with other parameters having negligible influences. A simplified equation was proposed for predicting this reduction factor, and hence the load-bearing capacity of eccentrically loaded columns. Comparisons between the proposed capacity predictions and the obtained experimental and numerical results revealed very good agreement.

\section{Acknowledgement}

The research presented in this paper was sponsored by the National Natural Science Foundation (No. 51508131), Excellent Young Talents Program of Harbin Institute of Technology and the China Scholarship Council (CSC); their financial support is highly appreciated.

\section{Appendix}

A typical $N-M$ interaction curve for a STCRC column is shown in Fig.A1, in which $N$ and $M$ are the applied axial load and moment, respectively, $N_{\mathrm{u}}$ is the load-bearing capacity of the axially loaded column and $M_{\mathrm{u}}$ is the pure bending capacity.

The curve $a b$ can be simplified to a linear form, as given by Eq.(12).

$$
\frac{N}{N_{\mathrm{u}}}+a \frac{M}{M_{\mathrm{u}}}=1.0
$$

where $a$ is an interaction factor. 


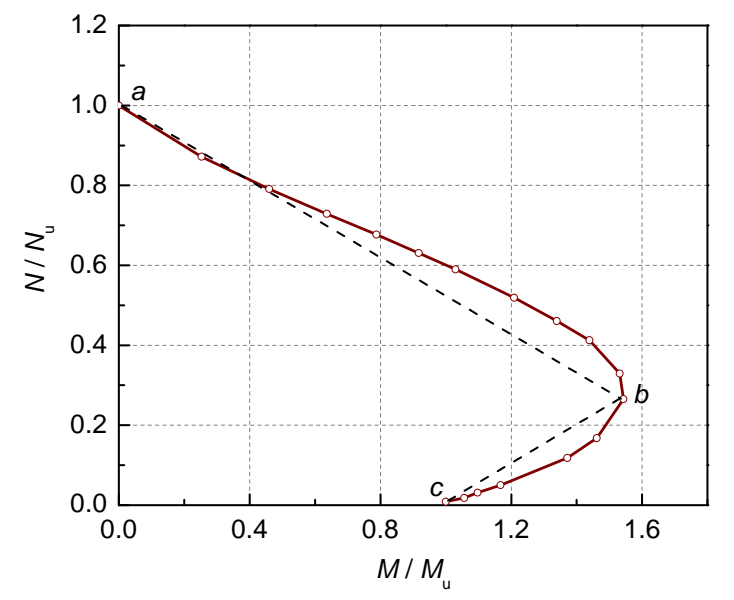

Fig.A1 Typical $N-M$ interaction curve for a STCRC column

Since $M=N \cdot e$ and $M_{\mathrm{u}}=\beta N_{\mathrm{u}} \cdot D$, where $e$ is load eccentricity, $\beta$ is a factor and $D$ is the outer diameter, then Eq.(12) can be written as:

$$
\frac{N}{N_{\mathrm{u}}}\left(1+a \frac{e}{\beta D}\right)=1.0
$$

and then

$$
\chi_{\mathrm{e}}=\frac{N}{N_{\mathrm{u}}}=\frac{1}{1+a \frac{e}{\beta D}}=\frac{1}{1+\frac{a}{2 \beta} \cdot \frac{e}{r}}
$$

where $r=D / 2$.

The factor $\frac{a}{2 \beta}$ was simplified, following regression analysis, to 2.4 in this study, so the reduction factor $\chi_{\mathrm{e}}$, resulting in Eq.(8), was presented in Section 4 of the paper:

$$
\chi_{\mathrm{e}}=\frac{1}{1+2.4 \frac{e}{r}}
$$

\section{References}

[1] Liu FQ, Gardner L, Yang H. Post-fire behaviour of reinforced concrete stub columns confined by circular steel tubes. Journal of Constructional Steel Research 2014; 102: 82-103.

[2] Yang H, Liu FQ, Gardner L. Post-fire behaviour of slender reinforced concrete columns confined by circular steel tubes. Thin-Walled Structures 2015; 87: 12-29.

[3] Tomii M, Sakino K, Watanabe K, Xiao Y. Lateral Load Capacity of Reinforced Concrete Short Columns Confined by Steel Tube. In: Proceedings of the International Speciality Conference on 
Concrete Filled Steel Tubular Structures, Harbin, China, 1985; 19-26.

[4] Tomii M, Sakino K, Xiao Y, Watanabe K. Earthquake Resisting Hysteretic Behavior of Reinforced Concrete Short Columns Confined by Steel Tube. In: Proceedings of the International Speciality Conference on Concrete Filled Steel Tubular Structures, Harbin, China, $1985 ; 119-25$.

[5] Sakino K, Tomii M, Watanabe K. Sustaining Load Capacity of Plain Concrete Stub Columns Confined by Circular Steel Tube. In: Proceeding of the International Speciality Conference on Concrete Filled Steel Tubular Structures, Harbin, China, 1985; 112-8.

[6] Sun YP, Sakino K. Simplified design method for ultimate capacities of circularly confined high-strength concrete columns. ACI Special Publication 2000; 193: 571-85.

[7] Aboutaha RS, Machado R. Seismic resistance of steel confined reinforced concrete (SCRC) columns. The Structural Design of Tall Buildings 1998; 7(3): 251-60.

[8] Aboutaha RS, Machado RI. Seismic resistance of steel-tubed high-strength reinforced-concrete columns. Journal of Structural Engineering, ASCE 1999; 125(5): 485-94.

[9] Han LH, Yao GH, Chen ZB, Yu Q. Experimental behaviours of steel tube confined concrete (STCC) columns. Steel and Composite Structures 2005; 5(6): 459-84.

[10] Han LH, Qu H, Tao Z, Wang ZF. Experimental behaviour of thin-walled steel tube confined concrete column to RC beam joints under cyclic loading. Thin-walled Structures 2009; 47: 847-57.

[11] Liu JP, Zhou XH. Behavior and strength of tubed RC stub columns under axial compression. Journal of Constructional Steel Research 2010; 66: 28-36.

[12] Zhou XH, Liu JP. Seismic behavior and shear strength of tubed RC short columns. Journal of Constructional Steel Research 2010; 66: 385-97.

[13] Liu JP, Wang X D, Zhang SM. Behavior of square tubed reinforced-concrete short columns subjected to eccentric compression. Thin-Walled Structures 2015; 91: 108-15.

[14] Yu Q, Tao Z, Liu W, Chen ZB. Analysis and calculations of steel tube confined concrete (STCC) stub columns. Journal of Constructional Steel Research 2010; 66: 53-64. 
[15] ISO 834. Fire resistance tests - elements of building construction. Switzerland: International Organization for Standardization; 1975.

[16] Abrams MS. Compressive strength of concrete at temperatures to $1600 \mathrm{~F}$. ACI Special Publication 1971, 25: 33-58.

[17] Phan LT, Carino NJ. Review of mechanical properties of HSC at elevated temperature. Journal of Materials in Civil Engineering 1998, 10(1): 58-64.

[18] Tao J, Yuan Y, Taerwe L. Compressive strength of self-compacting concrete during high-temperature exposure. Journal of Materials in Civil Engineering 2010, 22(10): 1005-11.

[19] Huo JS, Zeng X, Xiao Y. Cyclic behaviours of concrete-filled steel tubular columns with pre-load after exposure to fire. Journal of Constructional Steel Research 2011, 67: 727-39.

[20] Huo JS, Zhang JG, Wang ZW, Xiao Y. Effects of sustained axial load and cooling phase on post-fire behaviour of reinforced concrete stub columns. Fire Safety Journal 2013, 59: 76-87.

[21] EN 1991-1-2. Eurocode 1: Actions on structures-part 1-2: General actions-actions on structures exposed to fire. Brussel: European Committee for Standardization; 2002.

[22] Lie TT. Fire resistance of circular steel columns filled with bar-reinforced Concrete. Journal of Structural Engineering, ASCE 1994; 120(5): 1489-509.

[23] Tao Z, Ghannam M. Refined FE model to predict the temperature field within concrete-filled steel tubes. In: Proceedings of 7th International Conference on Advances in Steel Structures, Nanjing, China, 2012; 781-9.

[24] Tao Z, Wang XQ, Uy B. Stress-strain curves of structural steel and reinforcing steel after exposure to elevated temperatures. Journal of Materials in Civil Engineering, ASCE 2013; 25(9): 1306-16.

[25] Han LH, Yao GH, Tao Z. Performance of concrete-filled thin-walled steel tubes under pure torsion. Thin-Walled Structures 2007; 45(1): 24-36.

[26] Lu H, Han LH, Zhao XL. Analytical behavior of circular concrete-filled thin-walled steel tubes subjected to bending. Thin-walled structures 2009, 47(3): 346-58.

[27] ACI 318M-08. Building code requirements for structural concrete and Commentary. USA: 
American Concrete Institute; 2008.

[28] Li W, Guo ZH. Experimental investigation of strength and deformation of concrete at elevated temperatures. Chinese Journal on Building Structures 1993; 14(1): 8-16. (in Chinese)

[29] Yang H, Liu FQ, Zhang SM, Lv XT. Experimental investigation of concrete-filled square hollow section columns subjected to non-uniform exposure. Engineering Structures 2013; 48: 292-312.

[30] Yang H, Liu FQ, Gardner L. Performance of concrete-filled RHS columns exposed to fire on 3 sides. Engineering Structures 2013; 56: 1986-2004.

[31] O'Shea MD, Bridge RQ. Design of circular thin-walled concrete filled steel tubes. Journal of Structural Engineering 2000; 126(11): 1295-303.

[32] Portolés JM, Romero ML, Bonet JL, Filippou FC. Experimental study of high strength concrete-filled circular tubular columns under eccentric loading. Journal of constructional steel research 2011; 67(4): 623-33.

[33] Portolés JM, Romero ML, Filippou FC, Bonet JL. Simulation and design recommendations of eccentrically loaded slender concrete-filled tubular columns. Engineering Structures 2011; 33: 1576-93.

[34] Han LH, Huo JS. Concrete-filled hollow structural steel columns after exposure to ISO-834 fire standard. Journal of Structural Engineering, ASCE 2003; 129(1): 68-78.

[35] GB50936-2014. Technical code for concrete filled steel tubular structures. China: Ministry of Housing and Urban-Rural Development; 2014. (in Chinese)

[36] Cai SH. Modern steel tube confined concrete structures. China Communications Press; 2003. (in Chinese) 


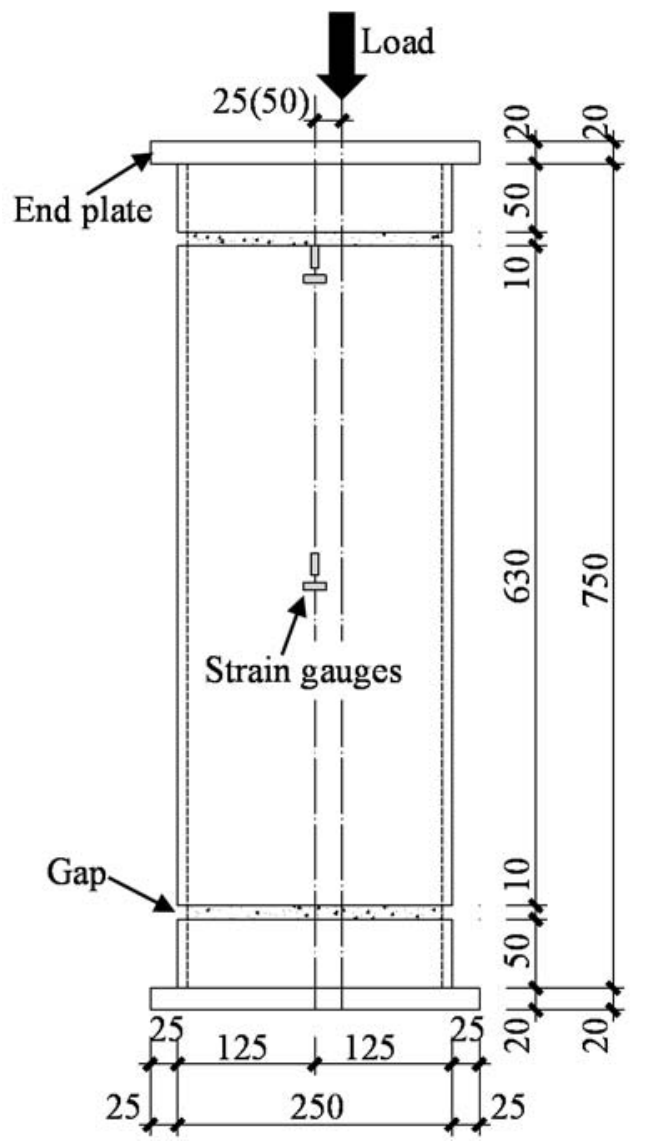

(a)

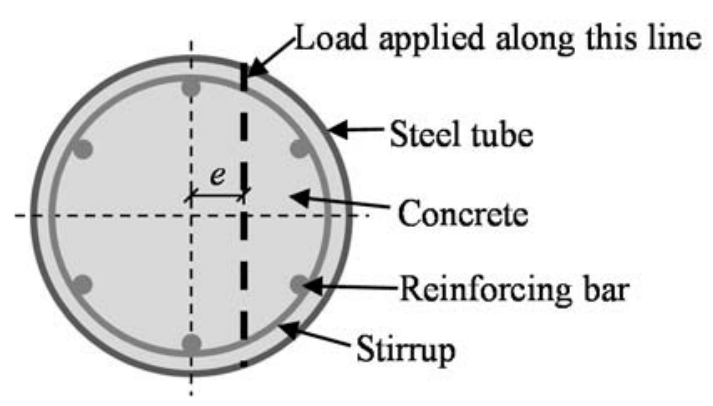

(b)

Fig.1 Dimensions of the test specimen: (a) elevation; and (b) cross-section (unit: mm). 


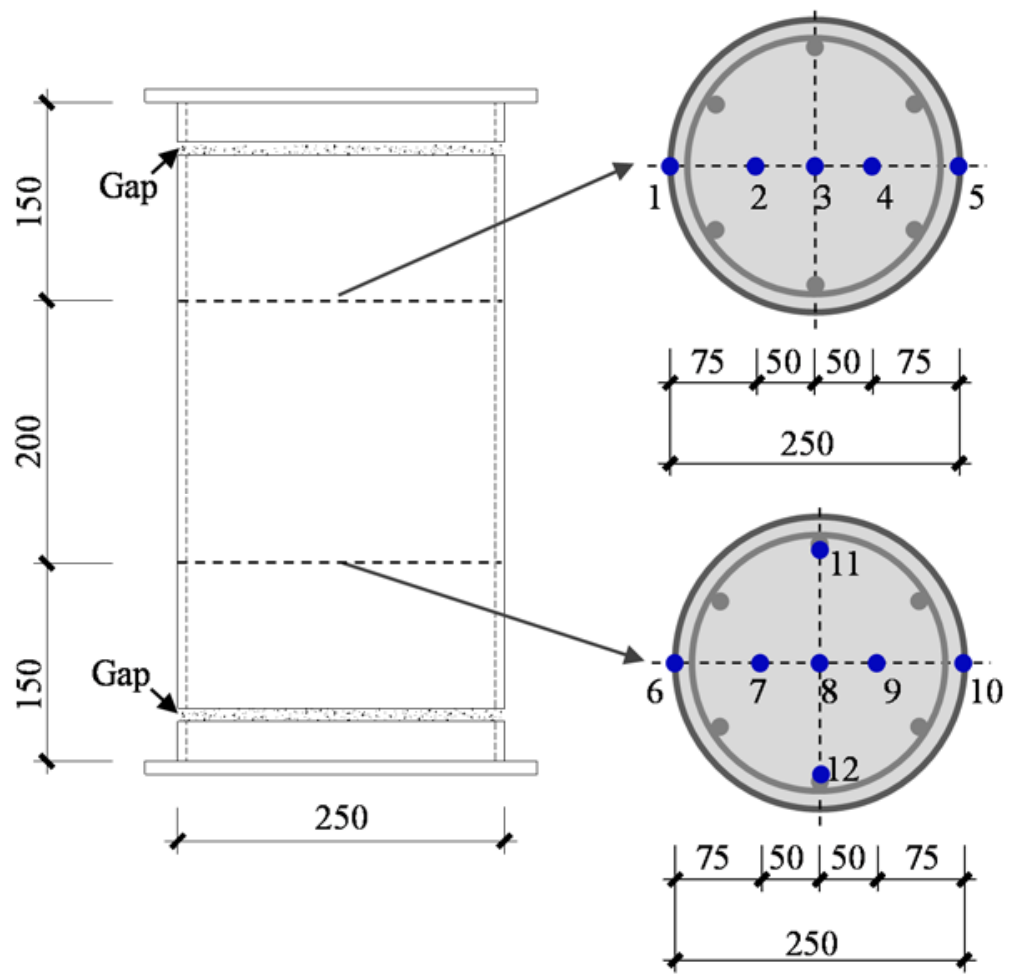

Fig.2 Layouts of thermocouples (unit: mm). 


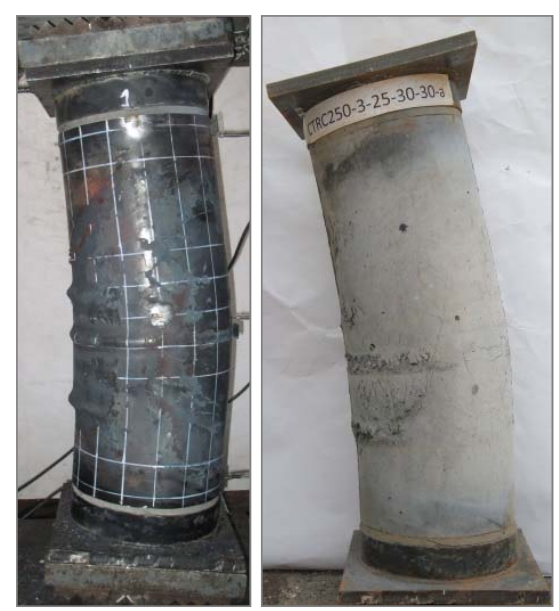

(a)

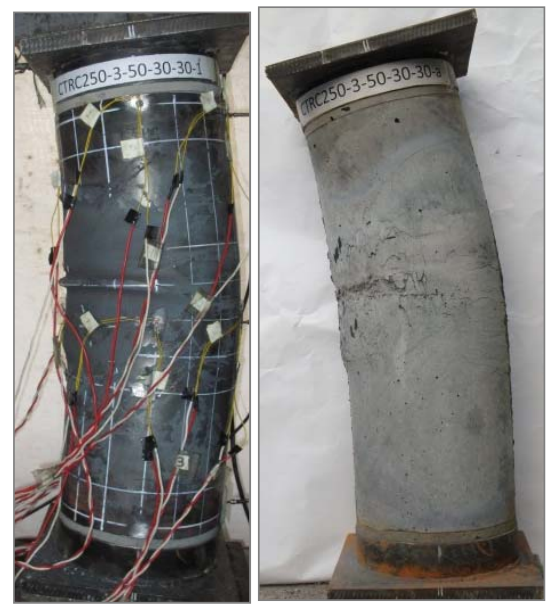

(b)

Fig.3 Typical failure modes of specimens (C30): (a) $e=25 \mathrm{~mm}$; and (b) $e=50 \mathrm{~mm}$. 


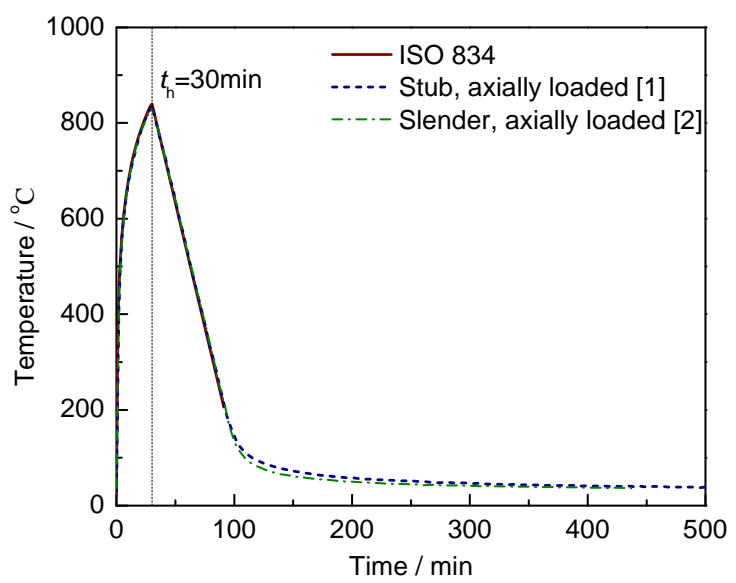

Fig.4 Comparisons of measured furnace temperatures with ISO 834 standard fire curve. 


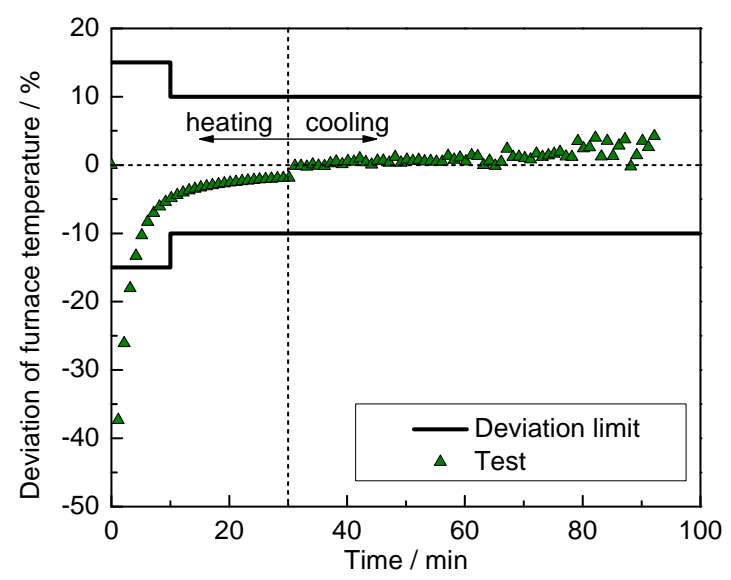

Fig.5 Deviation of the furnace temperature from the ISO 834 standard fire curve during the heating and cooling phases. 


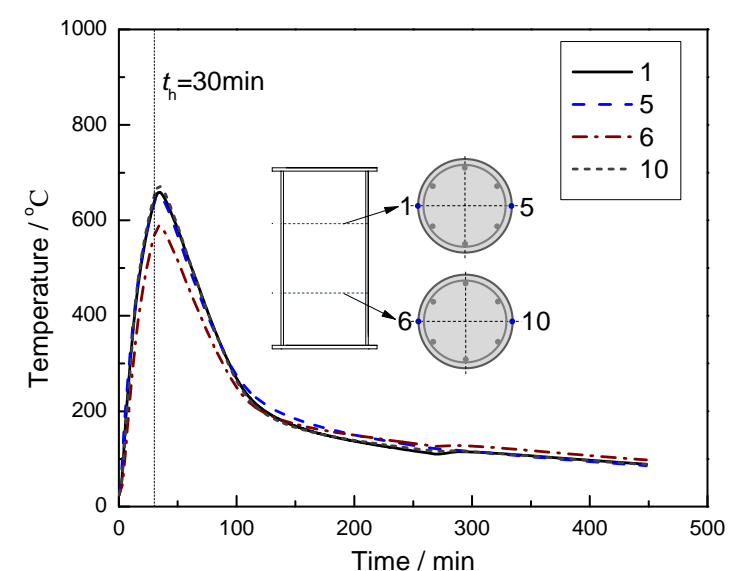

(a)

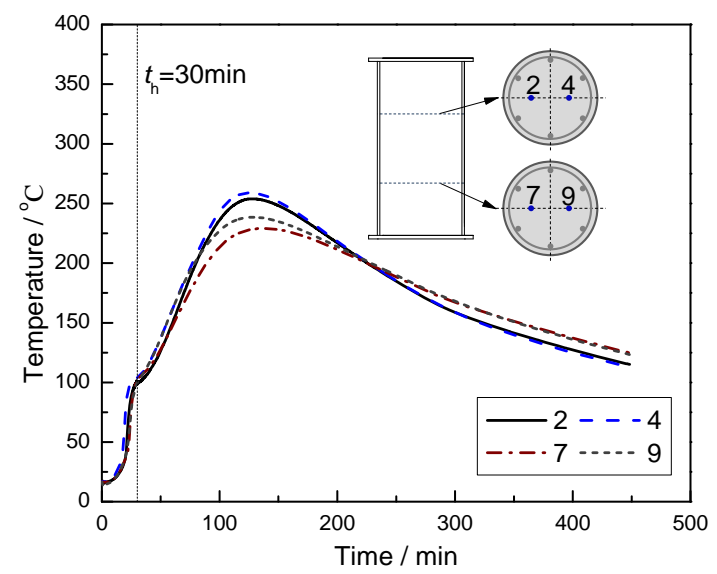

(c)

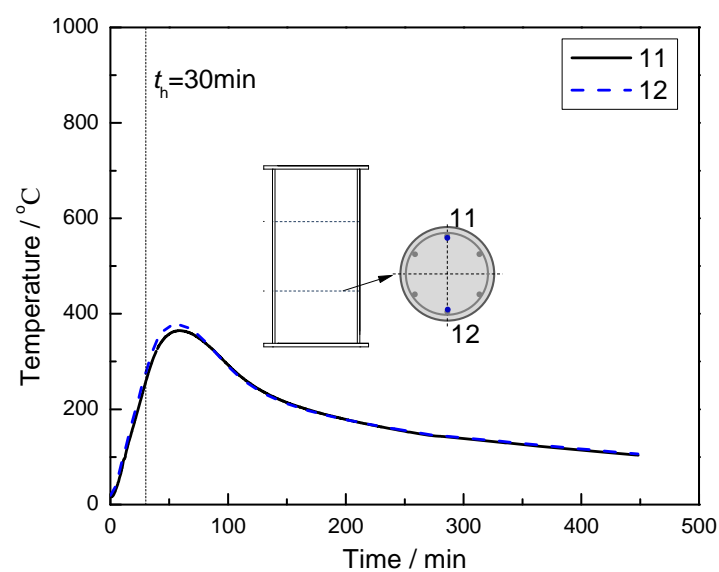

(b)

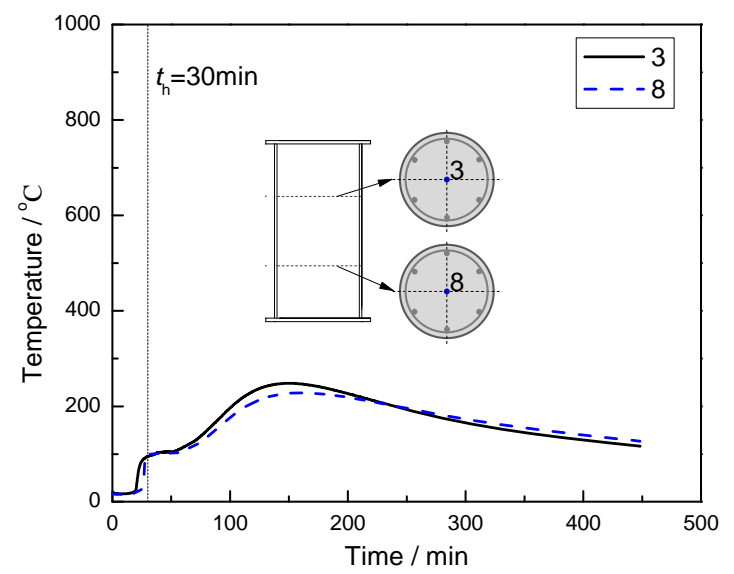

(d)

Fig.6 Measured cross-sectional temperatures [1]: (a) steel tube; (b) reinforcing bar; (c) and (d) concrete. 


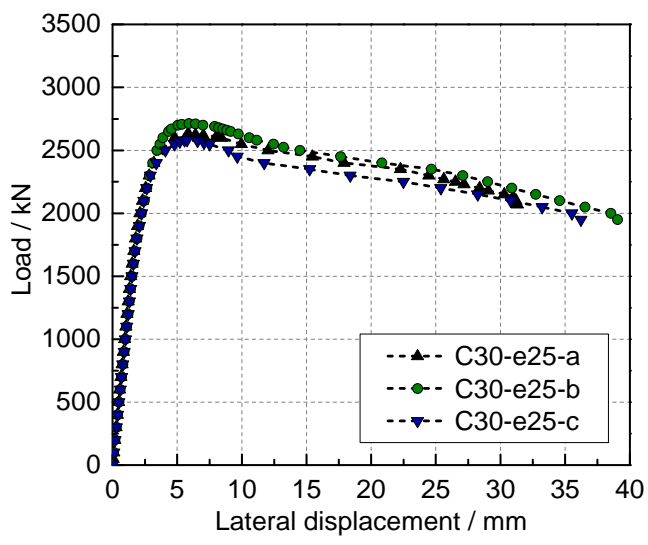

(a)

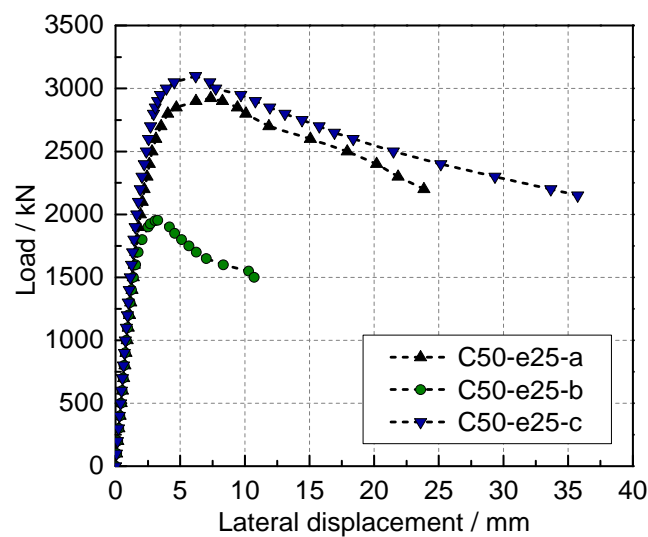

(c)

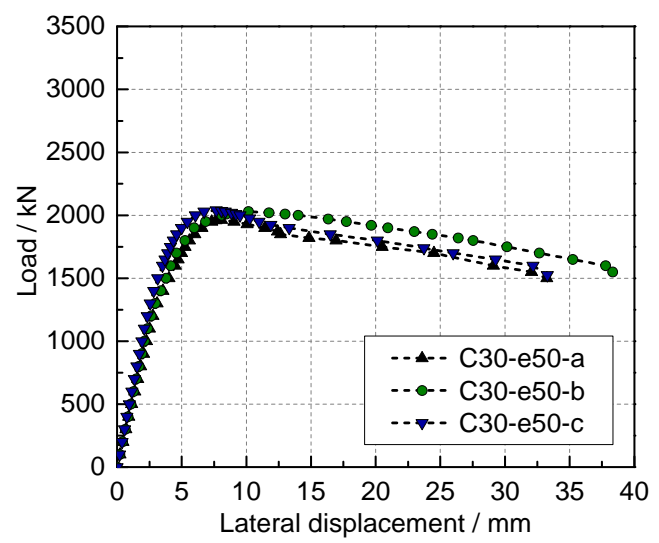

(b)

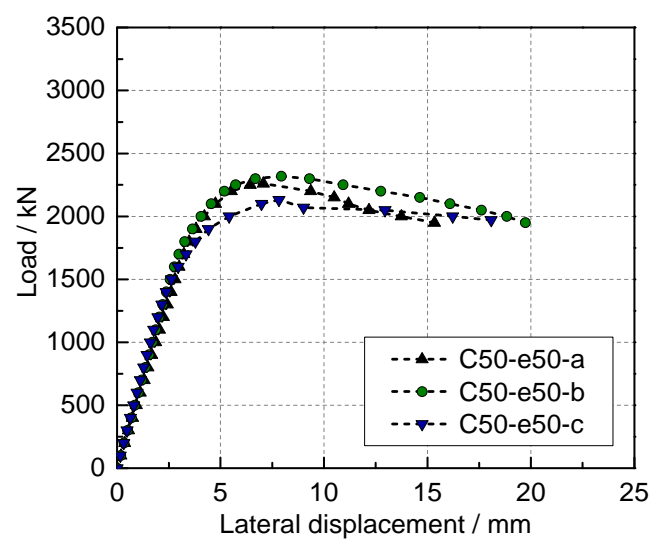

(d)

Fig.7 Load versus lateral displacement curves: (a) C30-e25; (b) C30-e50; (c) C50-e25; and (d) C50-e50. 


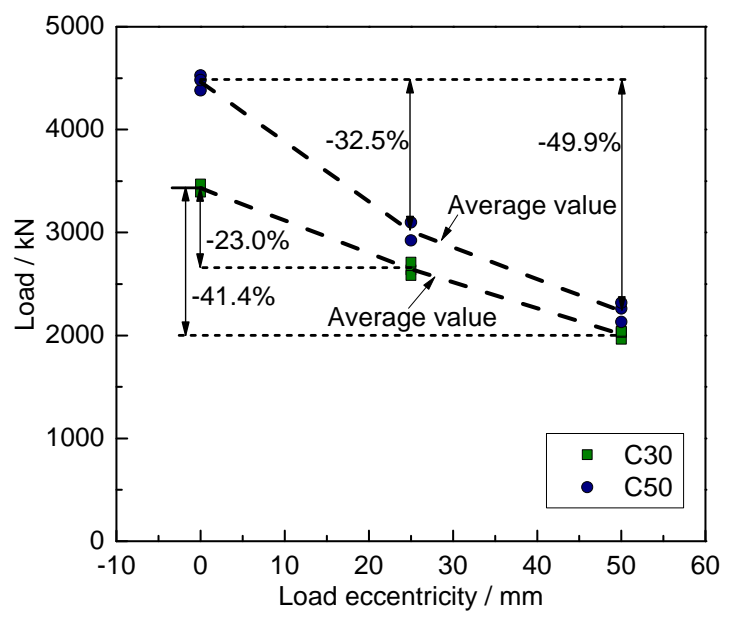

Fig.8 Influences of load eccentricity on load-bearing capacity. 


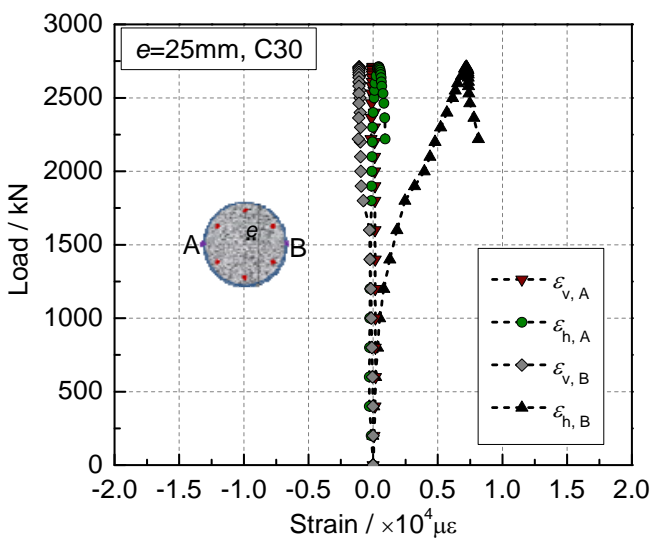

(a)

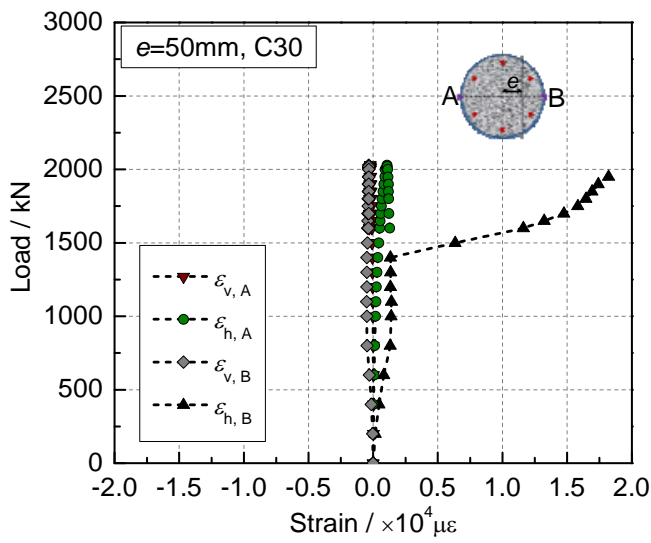

(c)

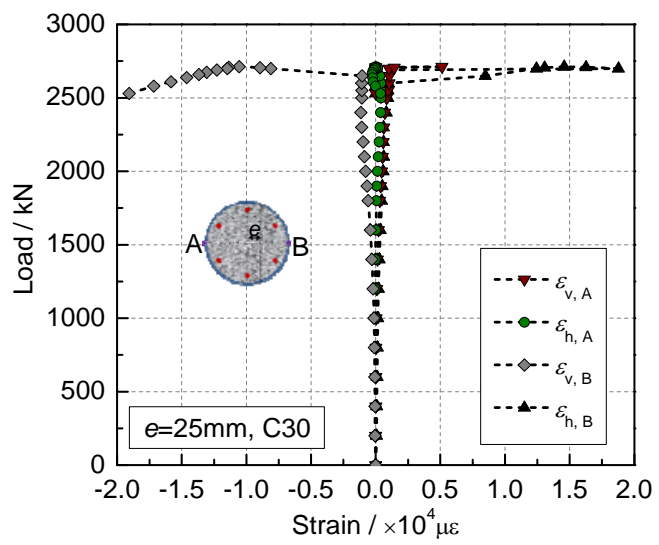

(b)

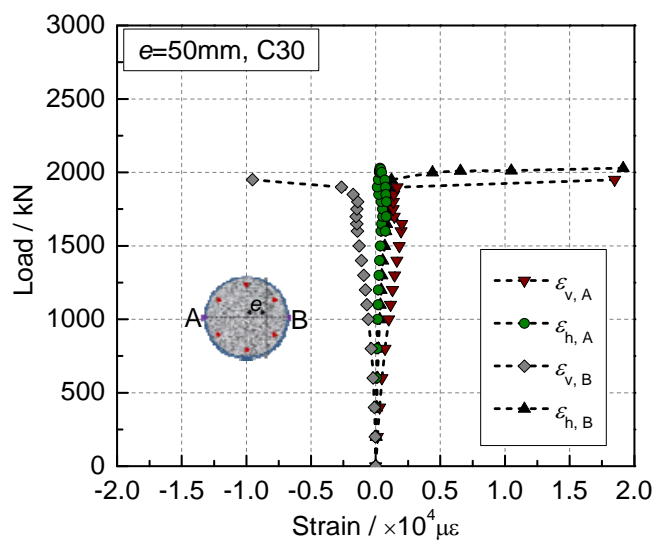

(d)

Fig.9 Vertical and horizontal strains in steel tube: C30-e25: (a) near gap; (b) mid-height; C30-e50: (c) near gap; and (d) mid-height. 


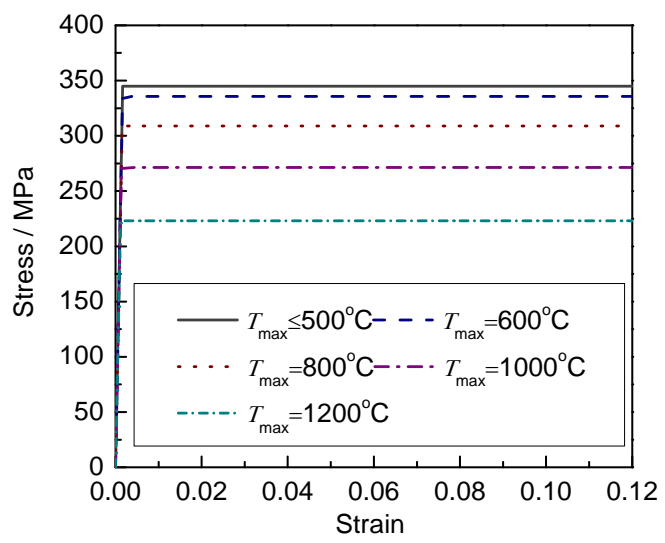

(a)

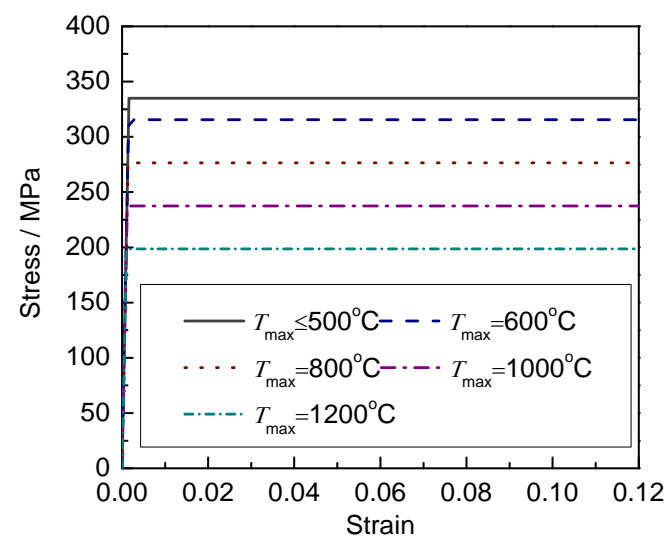

(b)

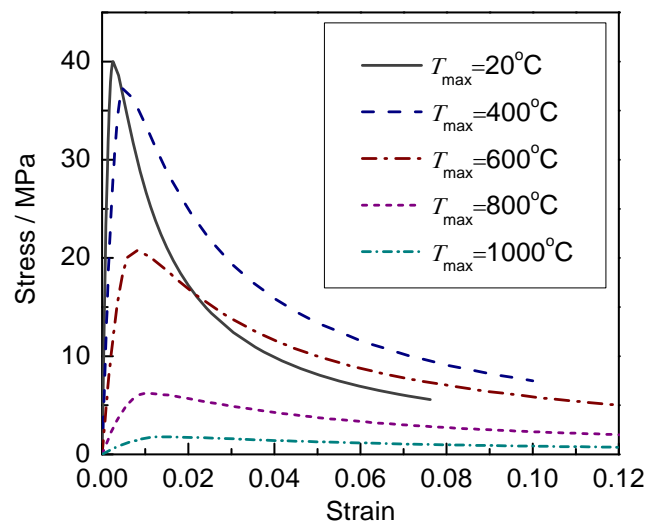

(c)

Fig.10 Uniaxial stress-strain curves of: (a) structural steel; (b) reinforcing bar; and (c) concrete. 


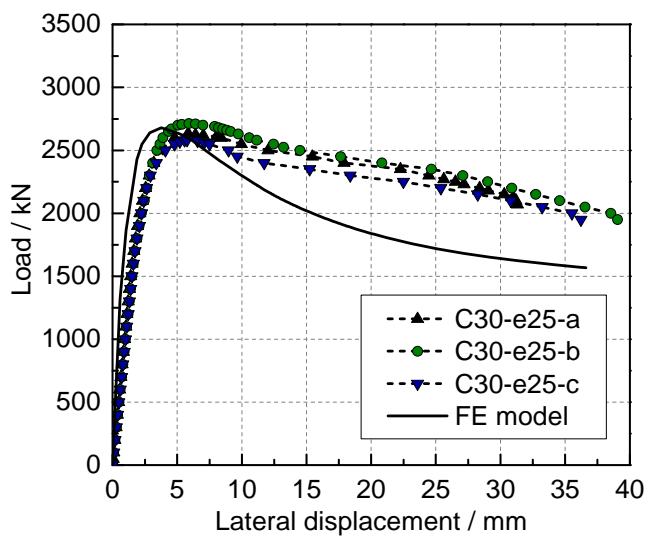

(a)

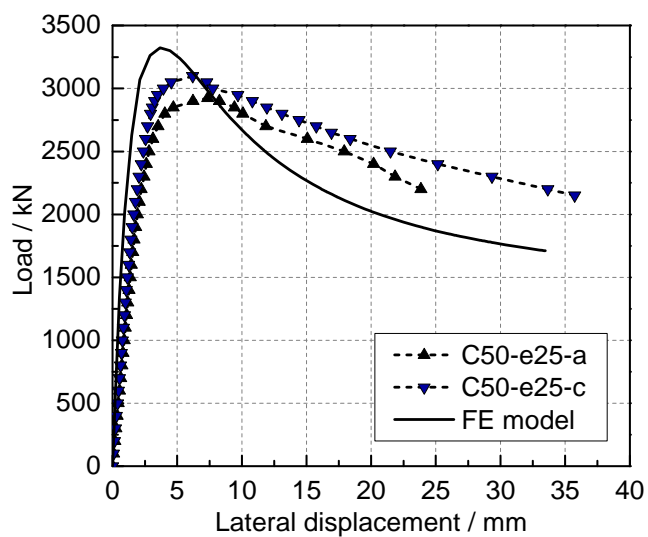

(c)

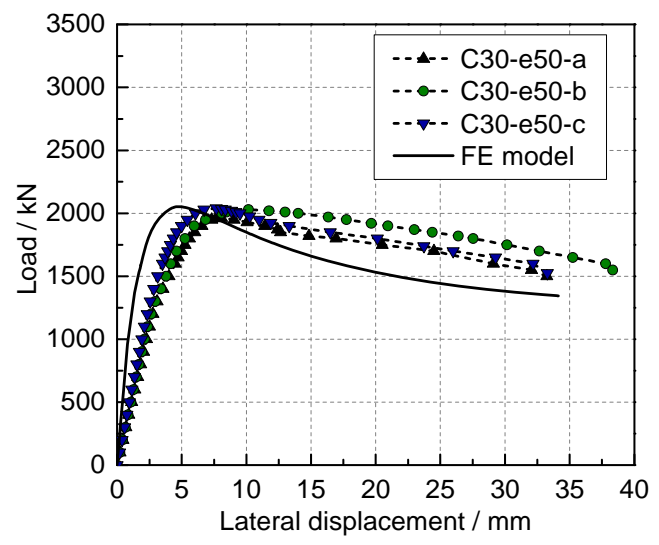

(b)

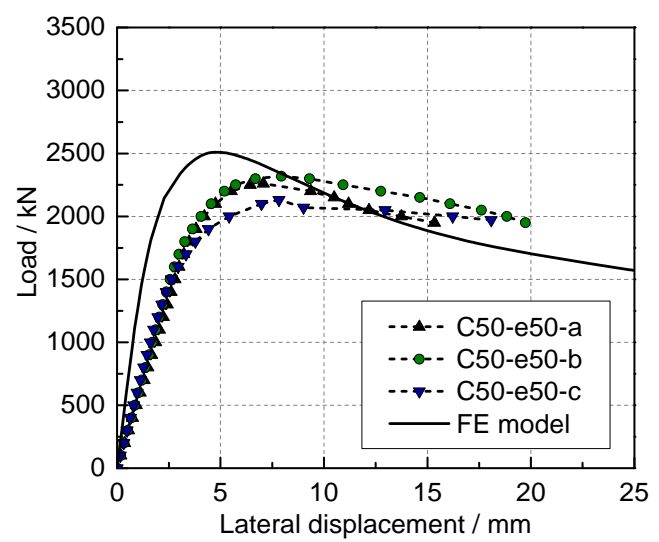

(d)

Fig.11 Comparisons of test and FE axial load-lateral displacement curves of STCRC columns: (a) C30-e25; (b) C30-e50; (c) C50-e25; and (d) C50-e50. 


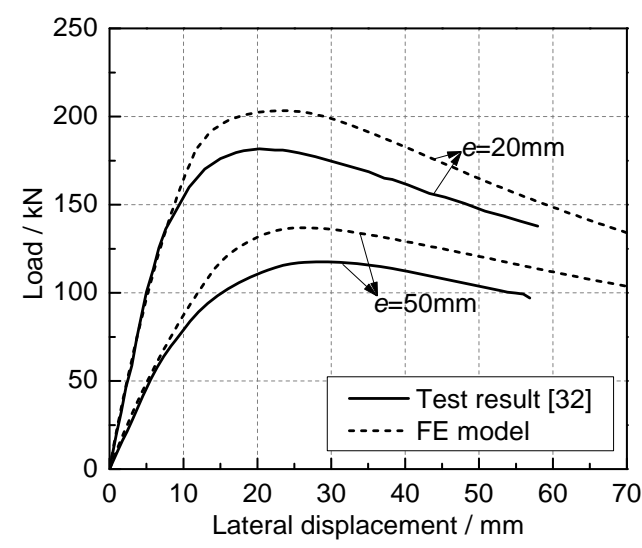

(a)

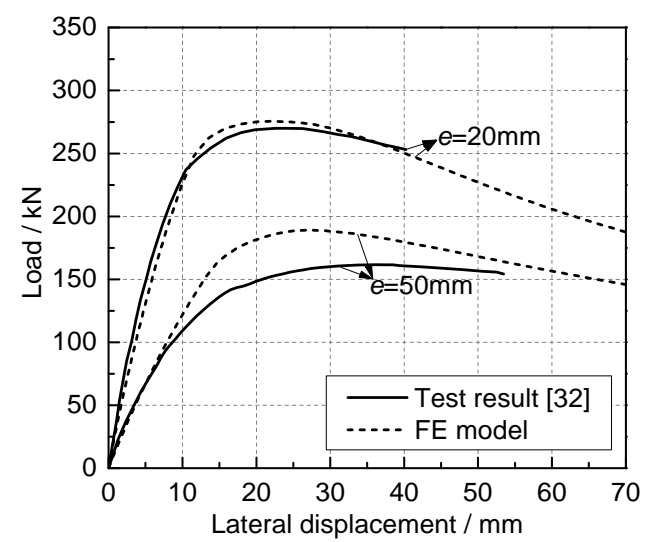

(c)

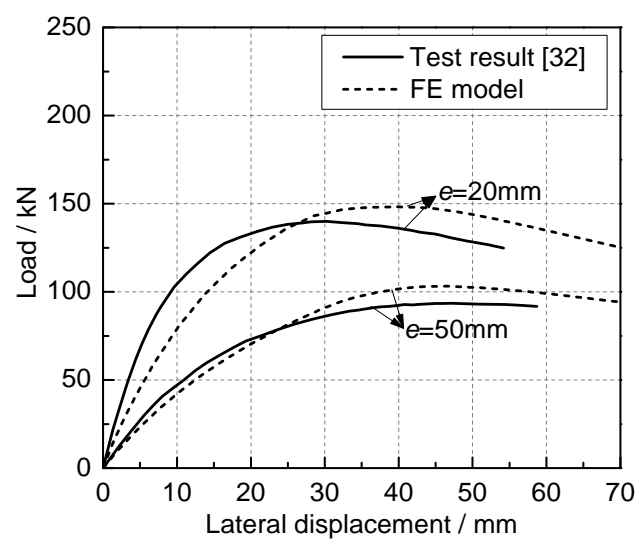

(b)

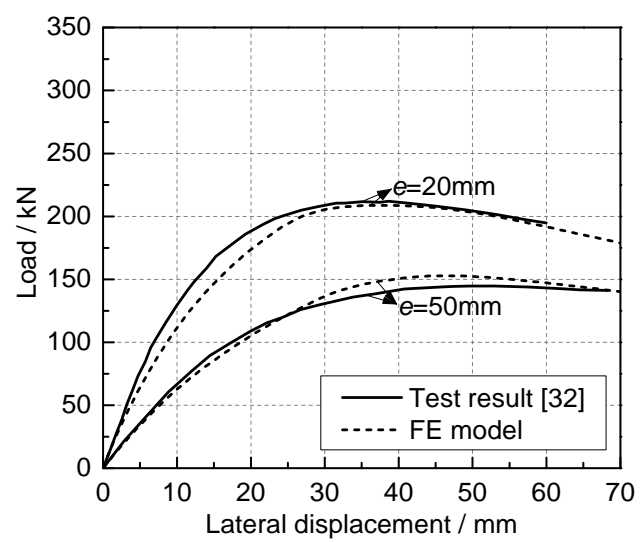

(d)

Fig.12 Comparisons of test and FE axial load-lateral displacement curves of CFST columns: (a) C100-3-2-30-20/50-1; (b) C100-3-3-30-20/50-1; (c) C100-5-2-30-20/50-1; and (d) C100-5-3-30-20/50-1. 


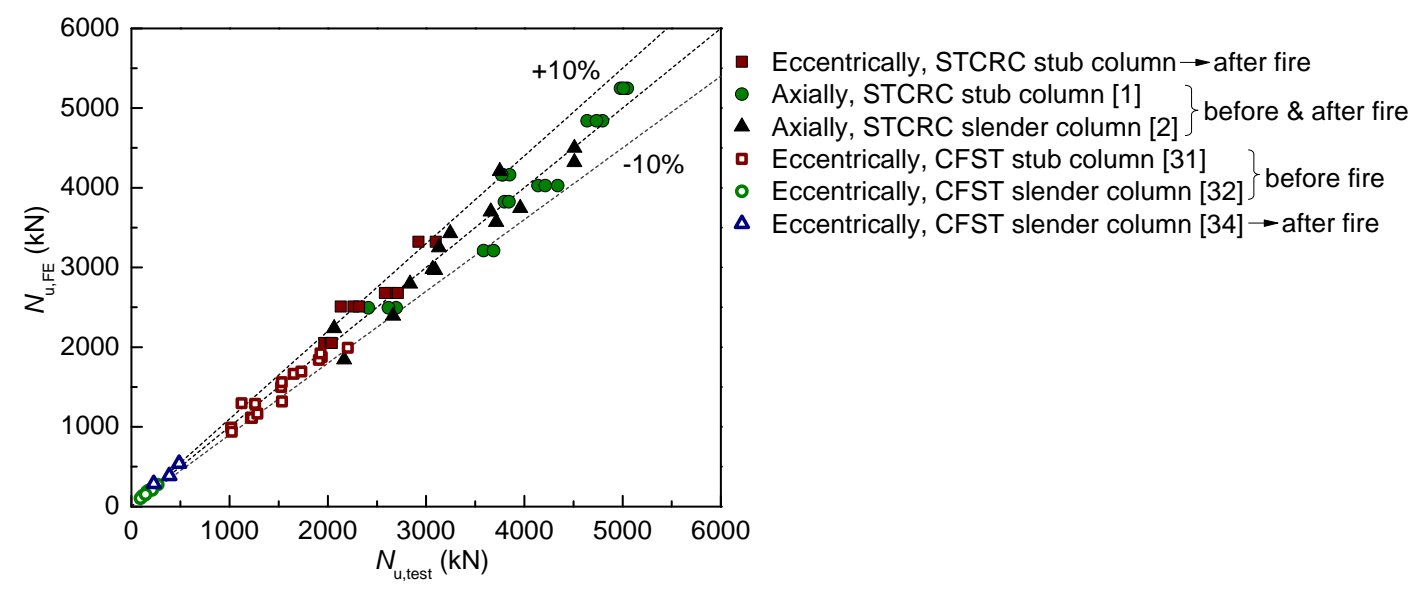

Fig.13 Comparisons of test and FE load-bearing capacities for STCRC columns and CFST columns. 


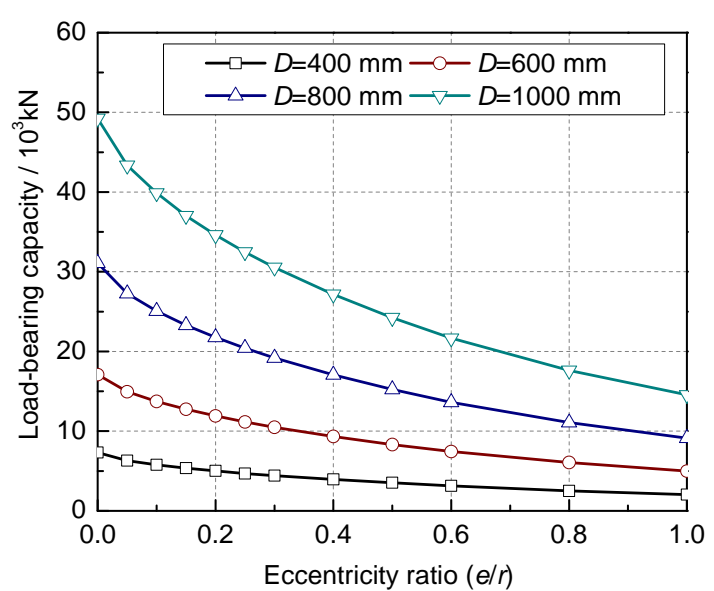

(a)

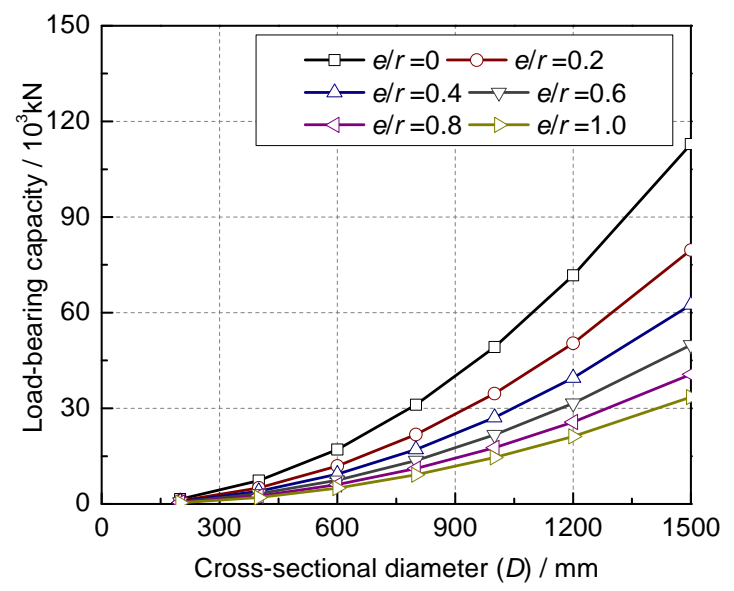

(c)

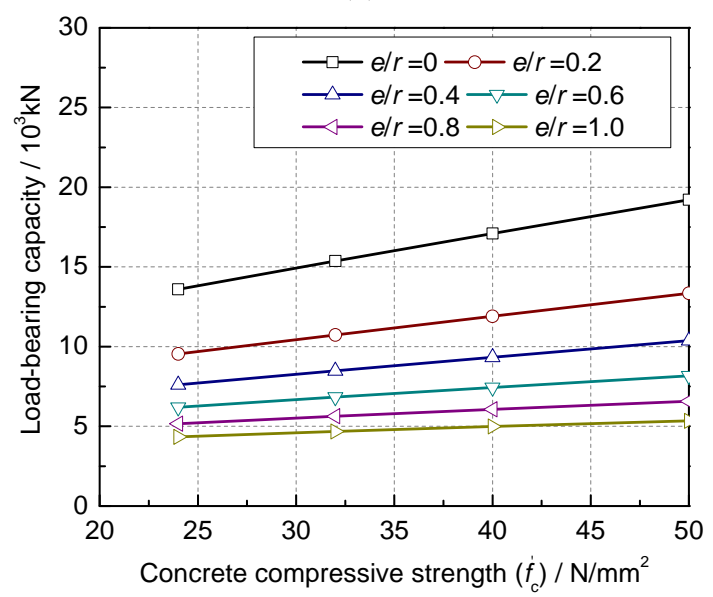

(e)

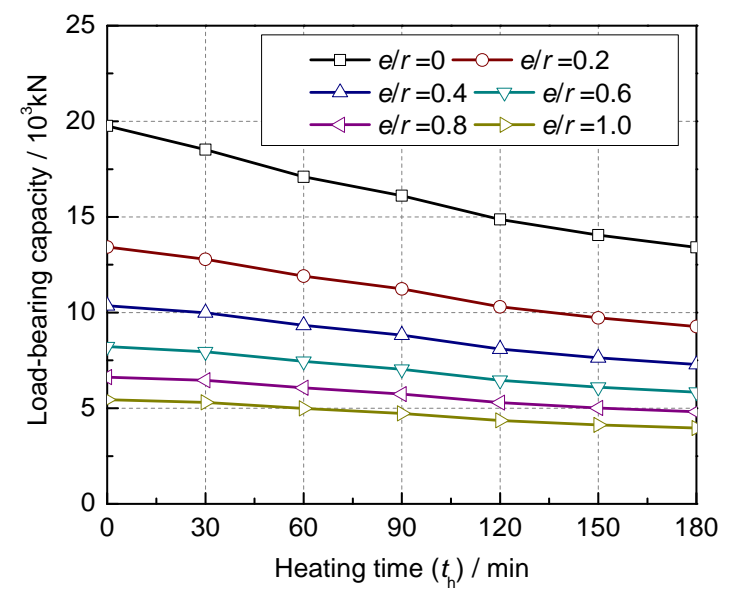

(b)

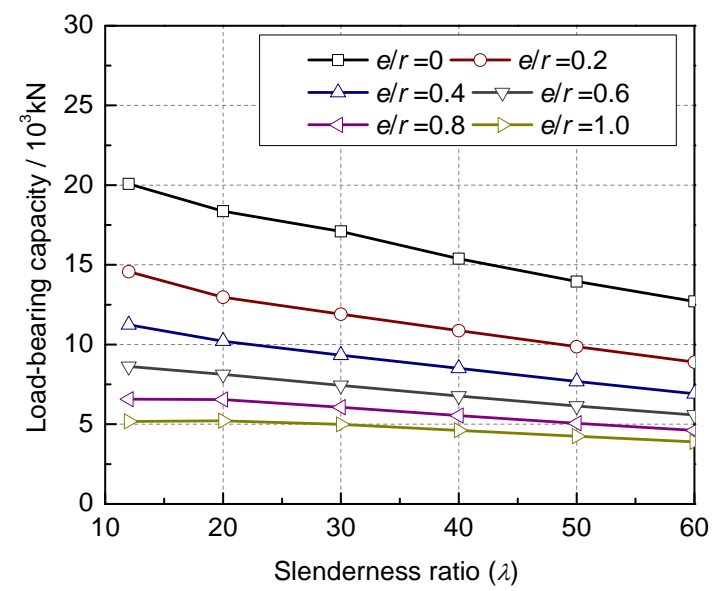

(d)

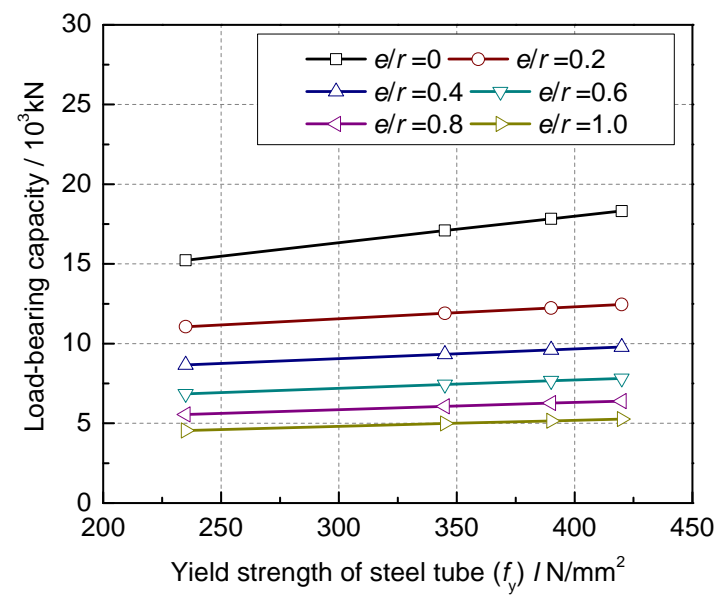

(f) 


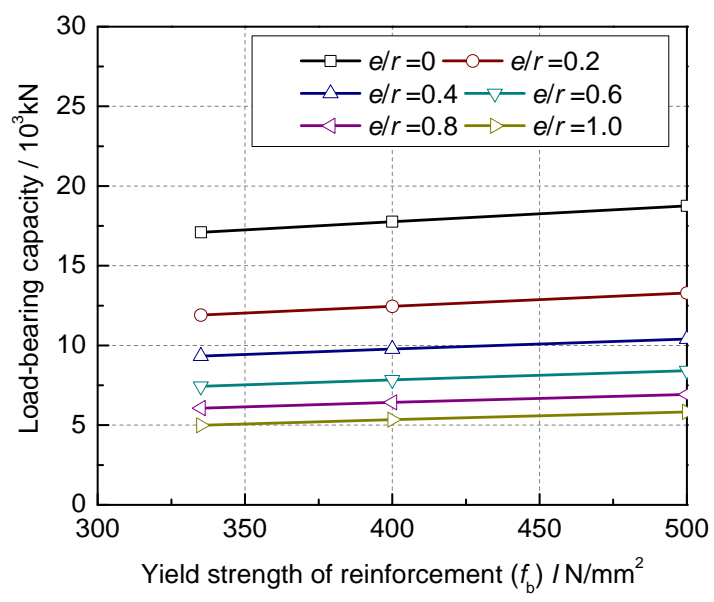

(g)

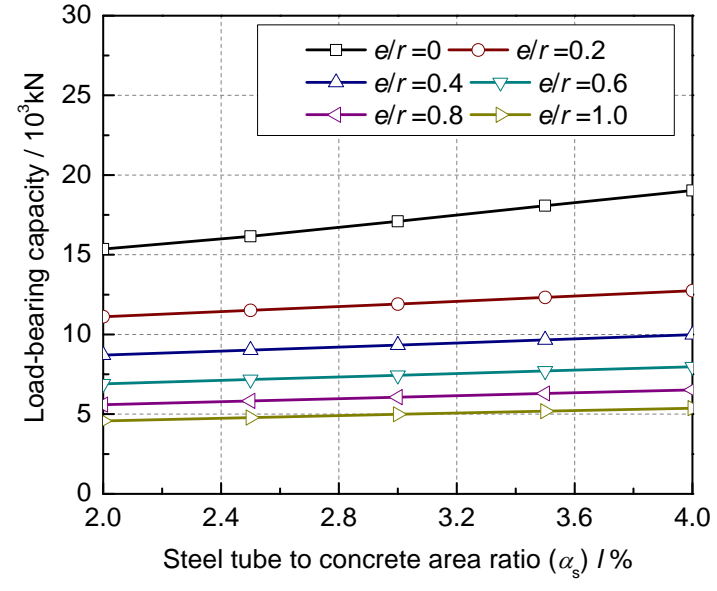

(h)

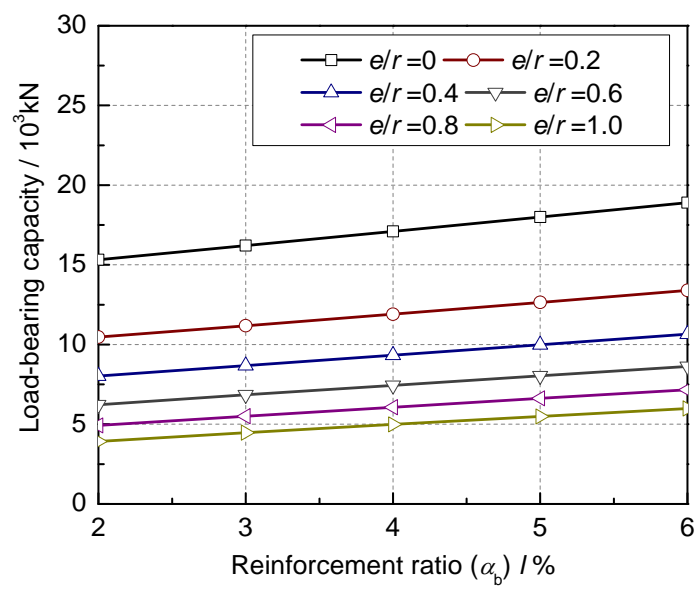

(i)

Fig.14 Influences of key parameters on the load-bearing capacity of STCRC columns: (a) eccentricity ratio; (b) heating time; (c) cross-sectional diameter; (d) slenderness ratio; (e) concrete strength; (f) yield strength of steel tube; (g) yield strength of reinforcement; (h) steel tube to concrete area ratio; and (i) reinforcement ratio. 


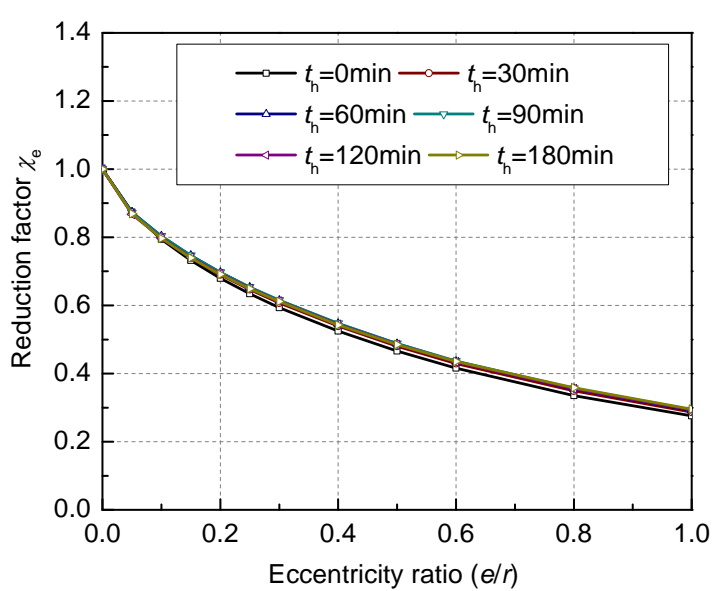

(a)

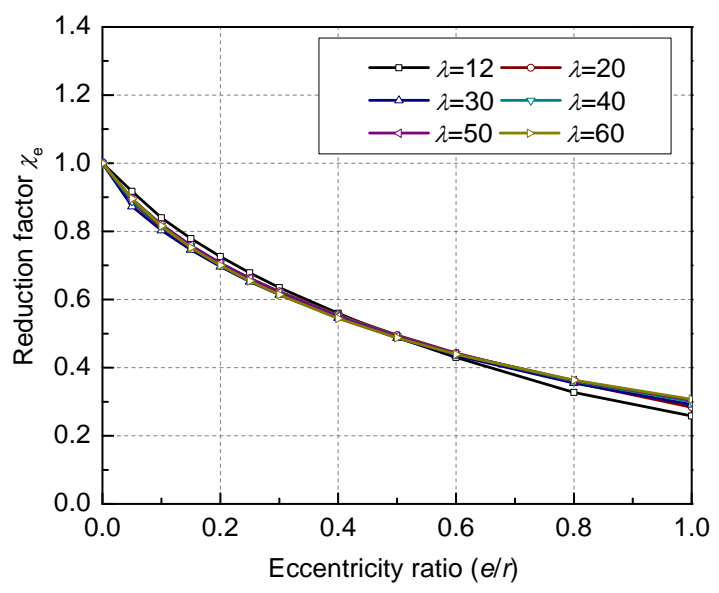

(c)

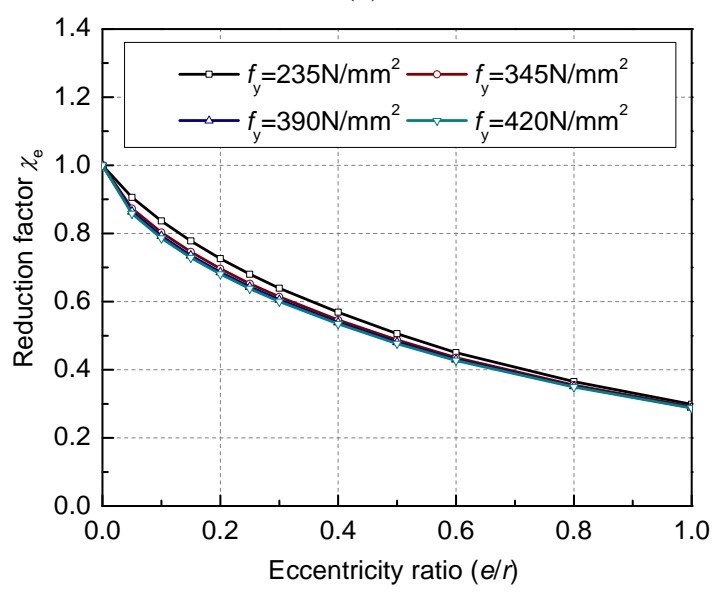

(e)

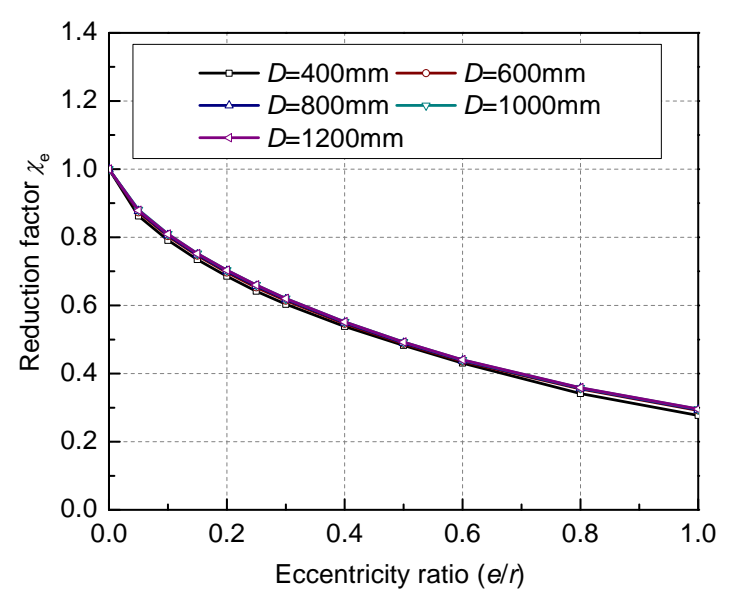

(b)

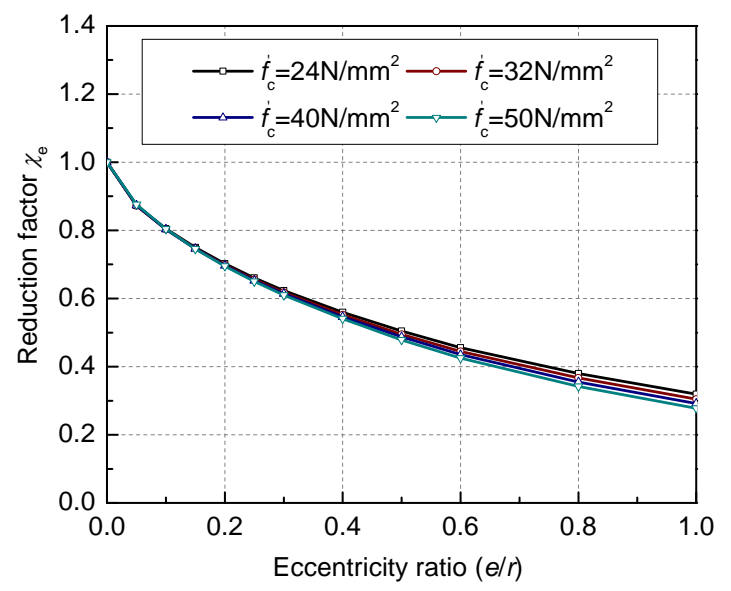

(d)

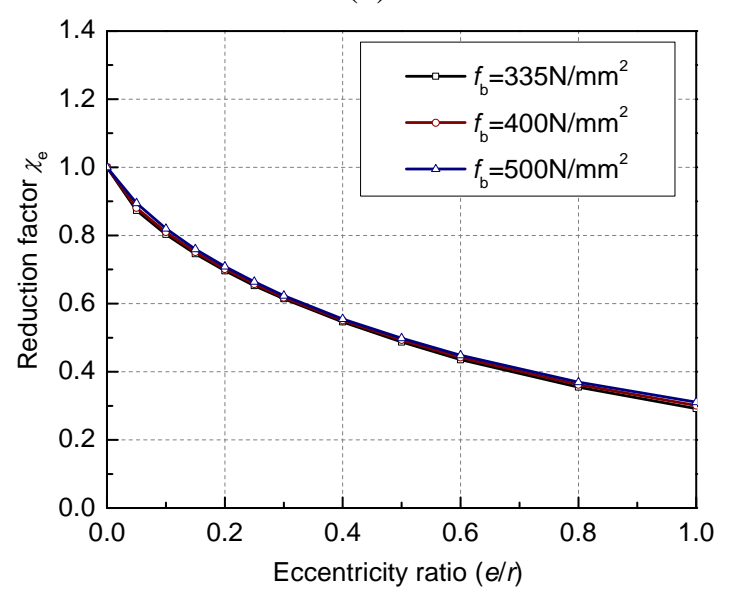

(f) 


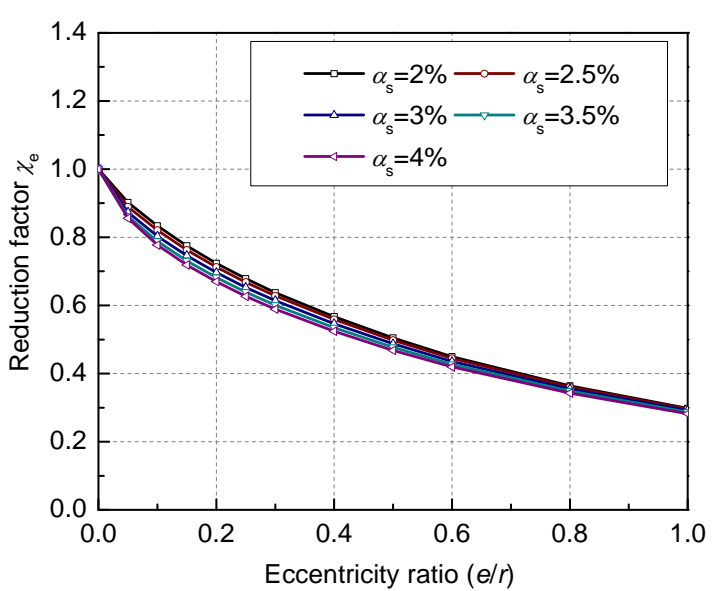

(g)

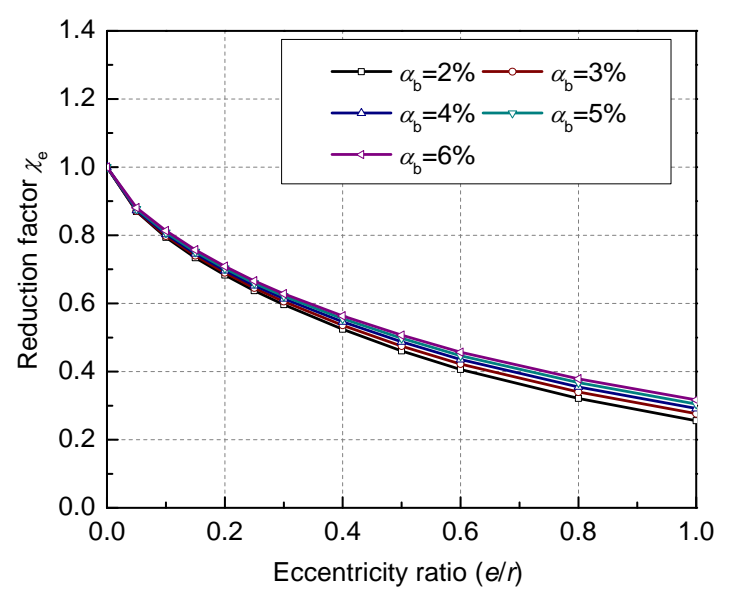

(h)

Fig.15 Influences of key parameters on the reduction factor $\chi_{\mathrm{e}}$ : (a) heating time; (b) cross-sectional diameter; (c) slenderness ratio; (d) concrete strength; (e) yield strength of steel tube; (f) yield strength of reinforcement; (g) steel tube to concrete area ratio; and (h) reinforcement ratio. 


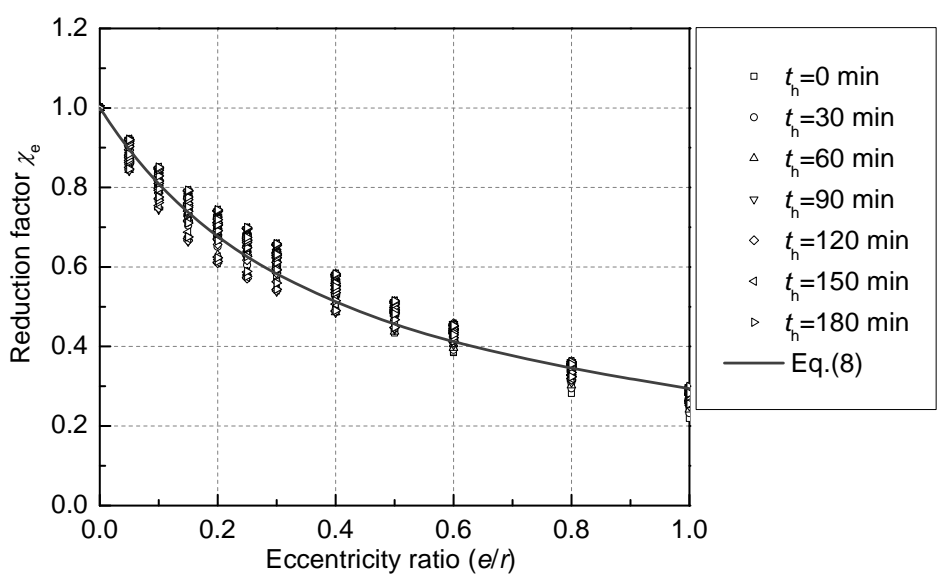

Fig.16 Comparisons between proposed reduction factor $\chi_{\mathrm{e}}$ (Eq.(8)) and FE results. 

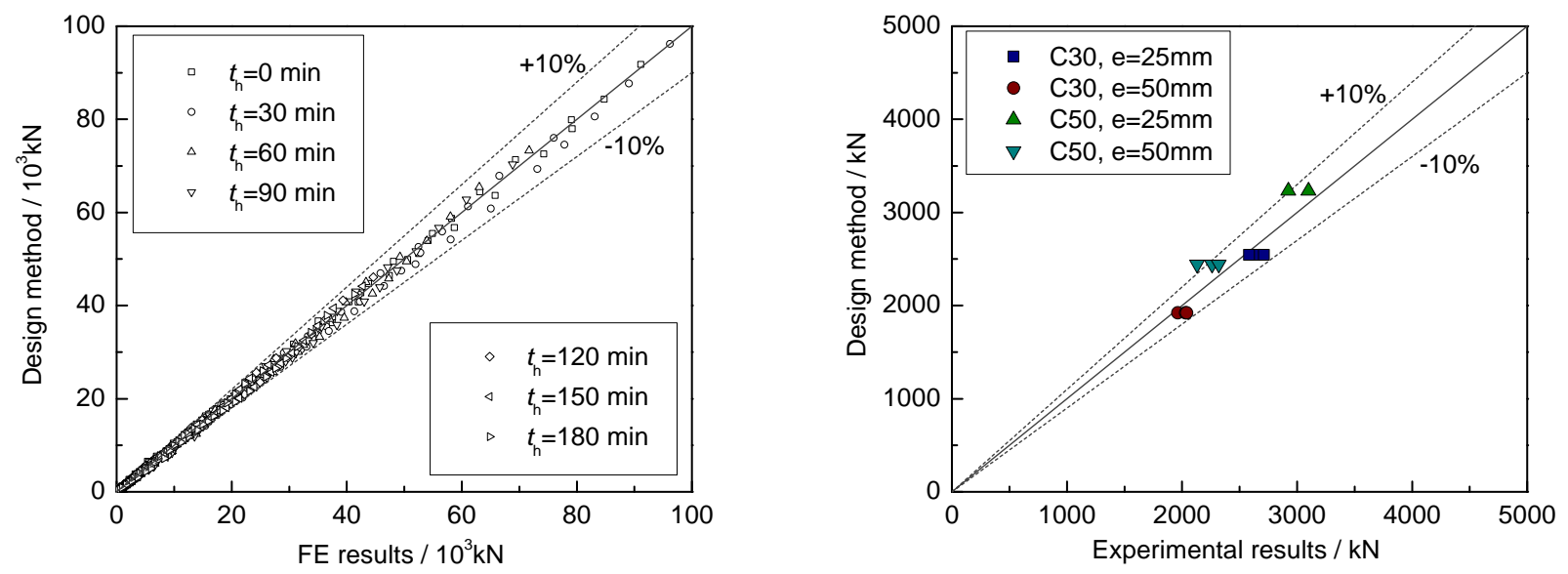

Fig.17 Comparisons of predicted load-bearing capacities of eccentrically loaded STCRC columns: (a) between design method and FE results; and (b) between design method and test results. 
Table 1 Detailed parameters of the test specimens

\begin{tabular}{|c|c|c|c|c|c|c|c|c|c|c|}
\hline \multirow{2}{*}{$\begin{array}{c}\text { Column } \\
\text { No. }\end{array}$} & \multicolumn{2}{|c|}{$D(\mathrm{~mm})$} & \multicolumn{2}{|c|}{$t_{\mathrm{s}}(\mathrm{mm})$} & \multirow{2}{*}{$\begin{array}{c}L \\
(\mathrm{~mm})\end{array}$} & \multirow{2}{*}{$\begin{array}{c}e \\
(\mathrm{~mm})\end{array}$} & \multirow{2}{*}{$\begin{array}{c}\alpha_{\mathrm{s}} \\
(\%)\end{array}$} & \multirow{2}{*}{$\begin{array}{c}\text { Reinforcing } \\
\text { Bars }\end{array}$} & \multirow{2}{*}{$\begin{array}{c}\alpha_{\mathrm{b}} \\
(\%)\end{array}$} & \multirow{2}{*}{$\begin{array}{c}t_{\mathrm{h}} \\
(\mathrm{min})\end{array}$} \\
\hline & Nominal & Measured & Nominal & Measured & & & & & & \\
\hline C30-e25-a & 250.0 & 249.5 & 2.20 & 2.18 & 750.0 & 25.0 & 3.62 & $6 \Phi 20$ & 3.98 & 30.0 \\
\hline C30-e25-b & 250.0 & 249.3 & 2.20 & 2.17 & 750.0 & 25.0 & 3.62 & $6 \Phi 20$ & 3.98 & 30.0 \\
\hline C30-e25-c & 250.0 & 249.7 & 2.20 & 2.18 & 750.0 & 25.0 & 3.62 & $6 \Phi 20$ & 3.98 & 30.0 \\
\hline C30-e50-a & 250.0 & 249.2 & 2.20 & 2.18 & 750.0 & 50.0 & 3.62 & $6 \Phi 20$ & 3.98 & 30.0 \\
\hline $\mathrm{C} 30-\mathrm{e} 50-\mathrm{b}$ & 250.0 & 249.5 & 2.20 & 2.19 & 750.0 & 50.0 & 3.62 & $6 \Phi 20$ & 3.98 & 30.0 \\
\hline C30-e50-c & 250.0 & 249.5 & 2.20 & 2.17 & 750.0 & 50.0 & 3.62 & $6 \Phi 20$ & 3.98 & 30.0 \\
\hline C50-e25-a & 250.0 & 249.7 & 2.20 & 2.20 & 750.0 & 25.0 & 3.62 & $6 \Phi 20$ & 3.98 & 30.0 \\
\hline C50-e25-b & 250.0 & 249.2 & 2.20 & 2.18 & 750.0 & 25.0 & 3.62 & $6 \Phi 20$ & 3.98 & 30.0 \\
\hline C50-e25-c & 250.0 & 249.2 & 2.20 & 2.17 & 750.0 & 25.0 & 3.62 & $6 \Phi 20$ & 3.98 & 30.0 \\
\hline C50-e50-a & 250.0 & 249.3 & 2.20 & 2.16 & 750.0 & 50.0 & 3.62 & $6 \Phi 20$ & 3.98 & 30.0 \\
\hline C50-e50-b & 250.0 & 249.0 & 2.20 & 2.18 & 750.0 & 50.0 & 3.62 & $6 \Phi 20$ & 3.98 & 30.0 \\
\hline C50-e50-c & 250.0 & 249.8 & 2.20 & 2.17 & 750.0 & 50.0 & 3.62 & $6 \Phi 20$ & 3.98 & 30.0 \\
\hline
\end{tabular}


Table 2 Details of circular CFST stub columns subjected to eccentric load [31]

\begin{tabular}{lcccccc}
\hline & & & & & & \\
Column No. & $D(\mathrm{~mm})$ & $t_{\mathrm{s}}(\mathrm{mm})$ & $L(\mathrm{~mm})$ & $e(\mathrm{~mm})$ & $f_{\mathrm{y}}\left(\mathrm{N} / \mathrm{mm}^{2}\right)$ & $f_{\mathrm{c}}^{\prime}\left(\mathrm{N} / \mathrm{mm}^{2}\right)$ \\
\hline S30E250B & 165.0 & 2.82 & 662.0 & 7.0 & 363.3 & 48.3 \\
S30E150B & 165.0 & 2.82 & 661.5 & 17.2 & 363.3 & 48.3 \\
S30E280A & 165.0 & 2.82 & 661.0 & 9.4 & 363.3 & 80.2 \\
S30E180A & 165.0 & 2.82 & 661.0 & 17.9 & 363.3 & 80.2 \\
S10E250A & 190.0 & 0.86 & 743.5 & 7.4 & 210.7 & 41.0 \\
S10E150A & 190.0 & 0.86 & 744.5 & 13.9 & 210.7 & 41.0 \\
S10E280B & 190.0 & 0.86 & 747.0 & 8.6 & 210.7 & 74.7 \\
S10E180B & 190.0 & 0.86 & 746.5 & 17.9 & 210.7 & 74.7 \\
S12E250A & 190.0 & 1.13 & 745.0 & 8.5 & 185.7 & 41.0 \\
S12E150A & 190.0 & 1.13 & 745.5 & 18.9 & 185.7 & 41.0 \\
S16E150B & 190.0 & 1.52 & 743.5 & 15.5 & 306.1 & 48.3 \\
S16E180A & 190.0 & 1.52 & 745.0 & 14.3 & 306.1 & 80.2 \\
S20E250A & 190.0 & 1.94 & 742.5 & 8.6 & 256.4 & 41.0 \\
S20E150A & 190.0 & 1.94 & 745.5 & 16.2 & 256.4 & 41.0 \\
S20E280B & 190.0 & 1.94 & 744.0 & 10.0 & 256.4 & 74.7 \\
S20E180B & 190.0 & 1.94 & 744.5 & 20.8 & 256.4 & 74.7 \\
\hline
\end{tabular}


Table 3 Details of circular CFST slender columns subjected to eccentric load [32]

\begin{tabular}{ccccccc}
\hline Column No. & $D(\mathrm{~mm})$ & $t_{\mathrm{s}}(\mathrm{mm})$ & $L(\mathrm{~mm})$ & $e(\mathrm{~mm})$ & $f_{\mathrm{y}}\left(\mathrm{N} / \mathrm{mm}^{2}\right)$ & $f_{\mathrm{c}}^{\prime}\left(\mathrm{N} / \mathrm{mm}^{2}\right)$ \\
\hline C100-3-2-30-20-1 & 100.0 & 3.00 & 2135.0 & 20.0 & 322.0 & 32.7 \\
C100-3-2-30-50-1 & 100.0 & 3.00 & 2135.0 & 50.0 & 322.0 & 34.5 \\
C100-3-3-30-20-1 & 100.0 & 3.00 & 3135.0 & 20.0 & 322.0 & 39.4 \\
C100-3-3-30-50-1 & 100.0 & 3.00 & 3135.0 & 50.0 & 322.0 & 36.7 \\
C100-5-2-30-20-1 & 100.0 & 5.00 & 2135.0 & 20.0 & 322.0 & 35.4 \\
C100-5-2-30-50-1 & 100.0 & 5.00 & 2135.0 & 50.0 & 322.0 & 30.5 \\
C100-5-3-30-20-1 & 101.6 & 5.00 & 3135.0 & 20.0 & 320.0 & 38.7 \\
C100-5-3-30-50-1 & 101.6 & 5.00 & 3135.0 & 50.0 & 320.0 & 39.6 \\
\hline
\end{tabular}

